OAK RIDGE

NATIORAL

LABORATORY

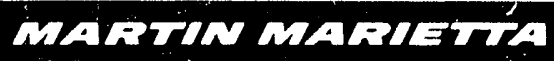

DRC2: A Code with Specialized Applications for Coupling Localized Monte Carlo Adjoint Calculations with Fluences from Two-Dimensional R-Z Discrete Ordinates Air-Over-Ground Calculations

C. O. Slater 
This report has been reproduced directly from the best available copy.

Available to DOE and DOE contractors from the Office of Scientific and Technical Information, P.O. Box 62, Oak Ridge, TN 37831; prices available from (615) 576-8401, FTS 626-8401.

Available to the public from the National Technical Information Service, U.S. Department of Commerce, 5285 Port Royal Rd., Springtield, VA 22161.

This report was prepared as an account of work sponsored by an agency of the United States Government. Neither the United States Government nor any agency thereot, nor any of their employees, makes any warranty, express or implied, or assumes any legal liability or responsibility for the accuracy, completeness, or usefulness of any information, apparatus, product, or process disclosed, or represents that its use would not intringe privately owned rights. Reference herein to any specific commercial product, process, or service by trade name, trademark, mariufacturer, or otherwise, does not necessarily constilute or imply its endorsement, recommendation, or favoring by the United States Government or any agency thereot. The views and opinions of authors expressed herein do not necessarily state or reflect those of the United States Government or any agency thereot. 
Engineering Physics and Mathematics

\title{
DRC2: A Code With Specialized Applications for Coupling Localized Monte Carlo Adjoint Calculations With Fluences From Two-Dimensional R-Z Discrete Ordinates Air-Over-Ground Calculations
}

\author{
C. O. Slater \\ DATE PUBLISHED : JANUARY 1992
}

Prepared for the

Defense Nuclear Agency

Prepared by the

OAK RIDGE NATIONAL LABORATORY

Oak Ridge, Tennessee 37831 managed by

MARTIN MARIETTA ENERGY SYSTEMS, INC. for the

U.S. DEPARTMENT OF ENERGY under contract DE-AC05-84OR21400 


\section{ACKNOWLEDGEMENTS}

Thanks are due W. A. Rhoades for his helpful suggestions, his review of this document, and his overall guidance of the program. The code development and the writing of the code input section of this document were made easier because of the earlier work of M. B. Emmett. Input data for two test problems were supplied by J. O. Johnson and W. A. Rhoades. Technical reviewers, M. B. Emmett and J. O. Johnson, are thanked for their reviews and suggestions. Finally, the author gratefully acknowledges Carolyn Householder and Angela Alford for their efforts in assembling this manuscript for publication. 


\section{CONTENTS}

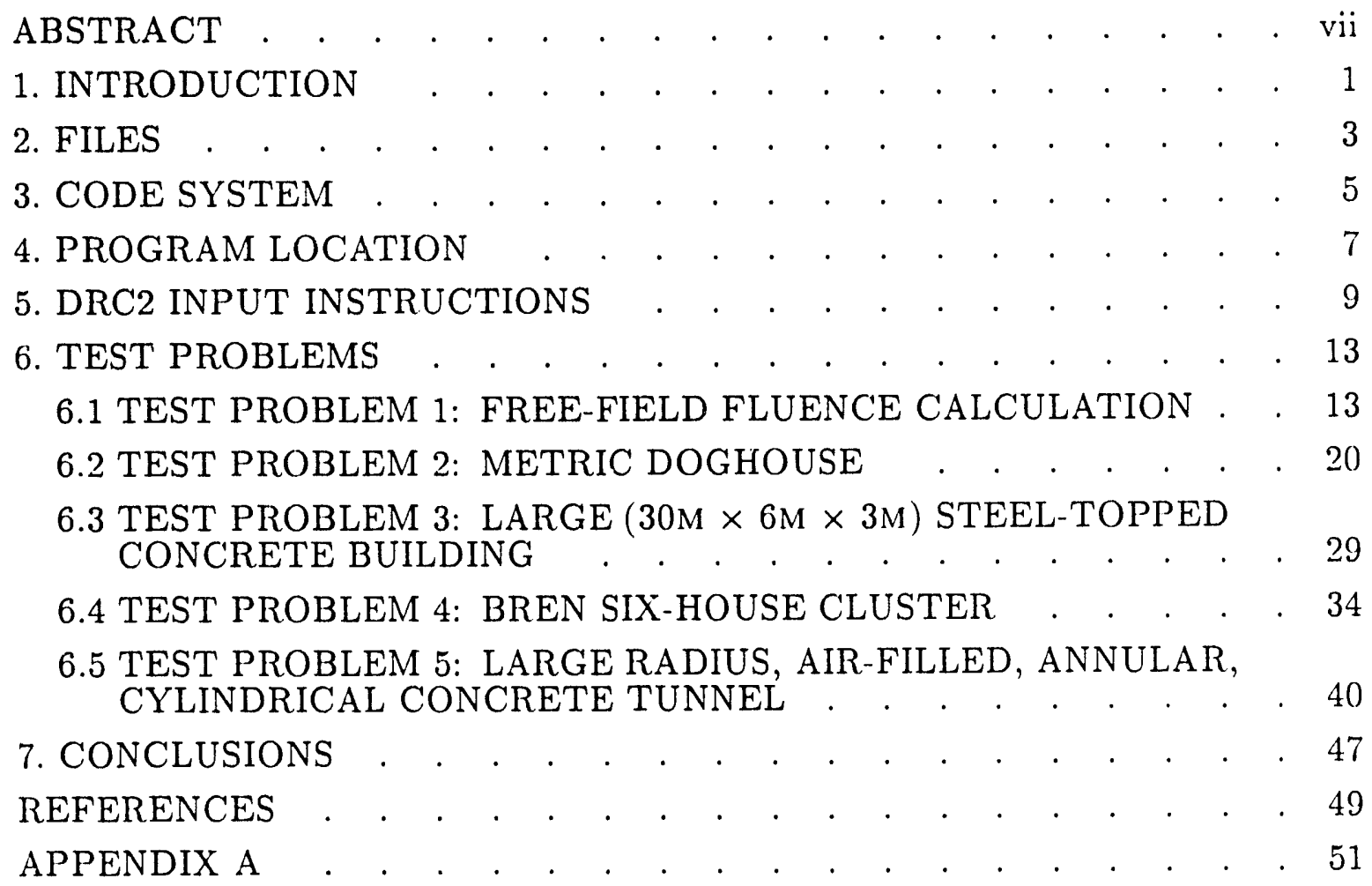




\section{ABSTRACT}

The DRC2 code, which couples MASH or MASHX adjoint leakages with DORT 2-D discrete ordinates forward directional fluences, is described. The forward fluences are allowed to vary both axially and radially over the coupling surface, as opposed to the strictly axial variation allowed by the predecessor DRC code. Input instructions are presented along with descriptions and results from several sample problems. Results from the sample problems are used to compare DRC2 with DRC, DRC2 with DORT, and DRC2 with itself for the case of $x-y$ dependence versus no $x-y$ dependence of the forward fluence. The test problems demonstrate that for small systems DRC and DRC2 give essentially the same results. Some significant differences are noted for larger systems. Additionally, DRC2 results with no $x-y$ dependence of the forward directional fluences are practically the same as those calculated by DRC. 


\section{INTRODUCTION}

The DRC2 code has been written to couple DORT ${ }^{1}$ forward fluences with adjoint leakages from a special version of the MORSE ${ }^{2}$ Monte Carlo computer code called MASHX. DRC2 has specialized applications because of the limited use of MORSE features, limitations on input parameters, and the manner in which the detectors are used. The code is an extensive modification of the $\mathrm{DRC}^{3}$ code, which has been used in the past for coupling. With DRC, the spatial dependence of the fluence was limited to axial variation. Linear interpolation was used to obtain the fluence at axial locations falling between the DORT fluence locations. However, since radial variation of the DORT fluences could be important for large vehicle systems or other large structures, the DRC2 code was developed to incorporate coupling with axially and radially varying DORT forward fluence fields. An option was included for specifying either linear or logarithmic interpolation or extrapolation of the fluences. In either case, linear is used when negatives are encountered.

An interim version of the MASH code ${ }^{4}$ (called MASHX) was used to provide data for testing the code. The MASHX code adds the $\mathrm{X}$ and $\mathrm{Y}$ coordinates of each adjoint particle escape location to the list of collision file parameters output along with five undefined and unused parameters. Thus, the collision file records, which are 1020 words in length, each contain data for 60 collisions at 17 words per collision. The number of words per collision and the record length are input parameters for DRC2.

DRC2 is set up to use the MASHX file either with or without X-Y dependence or the MASH file with its fewer collision file parameters ( 8 vs 10 defined parameters). In addition, DRC2 can calculate results for several range/orientations in a single pass through the code. Titles written to unit 11 are constructed from the input range and orientation data and the first 56 characters of the case title. The format is the expected one for an unpublished text-formatting and transmission-factorcalculating code (TFX).

The inclusion of X-Y dependent fluence fields in the DRC2 calculation and the calculation of results for several ranges and orientations in one pass through the code results in considerably more data in core than was the case with the DRC code. Therefore, if the allocated memory is not large enough to store all data in core, the code will perform the calculation "ex-core" with group blocking (i.e. the calculation is performed for a portion of the groups at a time until all group calculations are finished), provided data for at least one group will fit in core. There is probably little CPU charge penalty when the calculation is performed ex-core. The largest charge differences should be for IO (ex-core larger) and memory (incore larger). For example, for a 69-group calculation performed ex-core with three blocks (29 groups each for the first two blocks) and then in-core, charge ratios (in-core to ex-core) were $1.02,4.49,0.23$, and 1.51 for CPU, IO, memory, and total 
charges, respectively. A significant charge improvement was achieved for the ex-core calculation by reading the sequentially-processed forward fluence file with direct access rather than sequential. With sequential access and rewinding, the respective charge ratios were $9.37,13.9,2.36$, and 8.18 . Since the in-core calculation is likely to give the smallest total charge, whenever possible, one should allocate enough core to store fluence data for all groups. For the case cited, about 1.9 million words were required to store all data in core. 


\section{FILES}

DRC2 uses and creates several files. The files are assigned unit numbers 5, 6, $10,11,15$, and 24 . The respective default file names are ft05drc, ft06drc, ft $10 \mathrm{drc}$, $\mathrm{ft} 11 \mathrm{drc}, \mathrm{ft} 15 \mathrm{drc}$, and $\mathrm{ft} 24 \mathrm{msh}$. The names may be changed by specifying alternate names on the execute line as follows:

$$
\mathrm{drc} 2 \mathrm{f} 5=\mathrm{a}, \mathrm{f} 6=\mathrm{b}, \mathrm{f} 10=\mathrm{c}, \mathrm{f} 11=\mathrm{d}, \mathrm{f} 15=\mathrm{e}, \mathrm{f} 24=\mathrm{f}
$$

where the letters to the right of the equal signs represent the alternate names for the files. By unit numbers, the files are defined as follows:

\begin{tabular}{ll} 
Description of DRC2 Input and Output Files \\
\hline Unit \\
Number & File Description \\
\hline 5 & input file for DRC2 \\
6 & printed output file for DRC2 \\
10 & special output text file \\
11 & special output text file $^{3}$ fluence file \\
15 & VISTA $^{3}$. \\
24 & MASHX or MASH collision file
\end{tabular}

The special output text files contain formatted summary data for generating tabular output. Scratch files may be created and used, but their names are formed by the code and cannot be named by the user.

The interim MASHX code may be executed similarly: mashx $\mathrm{f} 5=\mathrm{a}, \mathrm{f} 6=\mathrm{b}, \mathrm{f} 8=\mathrm{c}, \mathrm{f} 24=\mathrm{d}$.

where the file descriptions by unit numbers are given below:

\section{Descriptions of MASHX Input and Output Files}

\begin{tabular}{|c|c|}
\hline \multicolumn{2}{|l|}{ Unit } \\
\hline Number & File Description \\
\hline 5 & input file for MASHX (default $=\mathrm{ft} 05 \mathrm{msh}$ ) \\
\hline 6 & printed output file for MASHX (default $=\mathrm{ft} 06 \mathrm{msh}$ ) \\
\hline 8 & cross-section library file (default $=\mathrm{ft} 08 \mathrm{msh})$ \\
\hline 24 & output collision file $($ default $=\mathrm{ft} 24 \mathrm{msh})$ \\
\hline
\end{tabular}

Scratch files are created and named by the code. 


\section{CODE SYSTEM}

Several codes are executed to produce the final DRC2 results. Files produced by one code may be used by one or more of the other codes executed in the calculational sequence. The production of the forward fluence file generally involves a calculational sequence executing the GIP $^{5}$, GRTUNCL $^{4}$, DORT $^{2}$, and VISTA ${ }^{3}$ codes. The VISTA code creates the fluence file that is used by DRC2. The MASH ${ }^{4}$ (or MASHX) code produces the collision file, and DRC2 couples the VISTA and MASH output files to produce the quantities of interest (fluence, dose, etc.). The sharing of files is outlined below, where " $I$ " and " $O$ " superscripts respectively indicate input and output for the codes. A code to the right uses data from a code to the left whenever the leftmost file on a line has a superscript " $O$ " and a file to the right has a superscript "I." The underlined file names are default Cray file names that are used if alternative names are not assigned on the execute line. File names in quotes (") are generic names for the ANISN- ("ansxs") and GIP-formatted ("gipxs") cross-section files. The other names refer to the code internal variable names for the files.

Sharing of Files by Codes

\begin{tabular}{|c|c|c|c|c|c|}
\hline GIP & GRTUNCL & DORT & VISTA & MASH & $\mathrm{DRC} 2$ \\
\hline $\begin{array}{l}\text { "ansxs"I } \\
\text { "gipxs"O* }\end{array}$ & $\begin{array}{l}\text { "gipxs"I } \\
\text { npso }\end{array}$ & $\begin{array}{l}\text { "gipxs"I } \\
\text { ntdsi }{ }^{I} \\
\text { nflsv }^{O} \\
\text { ntdir } O\end{array}$ & $\begin{array}{l}\text { nuncl }^{I} \\
\text { nflsv }^{I} \\
\text { naft }^{I} \\
\text { ndata } O\end{array}$ & ${\underline{\mathrm{ft} 08 \mathrm{msh}^{I}}}^{I}$ & $\frac{\mathrm{ft} 15 \mathrm{drc}}{\mathrm{ft} 24 \mathrm{msh}}^{I}$ \\
\hline
\end{tabular}

*GRTUNCL reads cross sections from unit 4; therefore in a calculational sequence, GIP should write cross sections to unit 4 and DORT, like GRTUNCL, should read cross sections from unit 4. 


\section{PROGRAM LOCATION}

The DRC2 and MASHX programs (source files and CTSS executable files) may be found in the cfs directory "/dos/vcs/slater" at LANL. Comments on field test experience are welcome. 


\section{DRC2 INPUT INSTRUCTIONS}

The following input instructions are patterned after draft documentation written by M. B. Emmett for the DRC code. In the input instructions, the term "vehicle" is used to refer to the object(s) or structure(s) perturbing the air-over-ground radiation field. It is modeled in the localized MASH calculation. A "vehicle system" includes the object(s) and the air and ground modeled in the MASH calculation.

Input Card A: (20A4) Title for this problem.

Input Card B: Free-form FIDO format - Begin with '**' in columns 2 and 3.
a. $x d$
- $x$-location $(\mathrm{cm})$ of the detector in MORSE geometry
b. yd
- $y$-location $(\mathrm{cm})$ of the detector in MORSE geometry
c. $z \mathrm{~d}$
- $z$-location $(\mathrm{cm})$ of the detector in MORSE geometry
d. zbot - bottom of coupling surface relative to MORSE geometry $(\mathrm{cm})$
e. ztop - top of coupling surface relative to MORSE geometry $(\mathrm{cm})$
f. iprt
- printout options
$0=$ print VISTA file control data and vehicle doses
$1=$ print VISTA file control data and free-field spectra
$2=$ print VISTA file control data, free-field spectra, vehicle doses
and dose spectra, and protection factors
$3=$ print VISTA file control data, vehicle doses, and protection
factors.

(Note: iprt must be 2 for unit 10 output)

g. watmx - maximum adjoint particle weight accepted

h. ndet - number of vehicle range/orientations

i. idif $-0 />0=$ same/different group structures for MORSE and VISTA data

j. ksiz - $k$-words of storage to be allocated ( 0 uses the default size of $500 \mathrm{k}$ words or the value used in a previous case. One should use 0 in follow-on cases if the same core allocation is desired.)

k. ibufsz - MASH or MASHX collision file record length in words (1000 for MASH and 1020 for MASHX)

1. nparm - number of parameters written on collision file ( 8 for MASH and 17 for MASHX)

m. idxy $-0=$ no $x-y$ data on collision file

$1=x-y$ data on collision file but no $x-y$ dependence in the coupling calculation 
$2=x-y$ data on collisica file and $x-y$ dependence in the coupling calculation

n. iww - number of responses desired (less than or equal to 10 . Note that a 0 implies 2 responses and iww must be $>0$ for unit 11 to be written).

o. $\mathrm{xq}-\mathrm{x}$-location $(\mathrm{cm})$ of the vehicle system rotation point relative to MORSE geometry

p. yq $-\mathrm{y}$-location $(\mathrm{cm})$ of the vehicle system rotation point relative to MORSE geometry

q. interp $-1 / 2=$ linear $/ \log$ flux interpolation

(Note: all the above parameters are read as real numbers and are converted to integers where required)

Input Card C: Ranges, MORSE-DORT Z offsets, and orientation arrays Free-form FIDO format - Begin with ${ }^{\text {(**', }}$ in columns 2 and 3.

Ranges (xo(i),i=1,ndet) $(\mathrm{cm})$ - DORT radii to the vehicle system rotation point for each case

MORSE-DORT $\mathrm{Z}$ offsets (zo(i),i=1,ndet) - DORT ground-air interface z-location $(\mathrm{cm})$ minus MORSE ground-air interface z-location $(\mathrm{cm})$. For simplicity, the MORSE ground-air interface should be placed at $z=0.0$. Then one need only specify the locations of the DORT ground-air interface.

Orientation array (alphe,(i), $i=1$,ndet) - orientation angles (degrees counterclockwise) of the vehicle system with respect to the positive portion of the DORT system $x$-axis.

Input Card D: (if idif $>0$ ) nneut,ngam - Free-form FIDO format - Begin with ' $\$ \$$ ' in columns 2 and 3.

nneut - group number of lowest energy neutron group in VISTA

ngam - group number of lowest energy gamma-ray group in VISTA

Input Card E: (if idif > 0) VISTA energy group boundaries (nog +2 entries)* Free-form FIDO - Begin with ${ }^{* *}$ ' in columns 2 and 3.

Enter neutron upper energy boundaries in descending order followed by gamma-ray upper energy boundaries in descending order followed by the lower energy boundaries of the 'nneut' neutron group and the 'ngam' gamma-ray group.

* nog is read from the VISTA file and is equal to the number of groups for which data is provided on the file. 
Input Card F: (20A4) Alphanumeric Title Information

Input Card G: (20A4) Title or units for total responses for all detectors

Input Card H: Title or units for each total response

Input Card I: Response Function - Free-form FIDO format - Begin with '**' in columns 2 and 3.

$(\operatorname{resp}(\mathrm{i}), \mathrm{i}=1, \mathrm{nmtg})$ - enter values in order of decreasing energy

Repeat Cards $\mathrm{H}$ and $\mathrm{I}$ for each response function.

Input Card J: Title of units for energy dependent fluence

To run additional cases, respecify all cards. In these follow-on cases, set ksiz on Card B to zero to maintain the same core allocation. 


\section{TEST PROBLEMS}

Several test problems were run to verify the correct operation of the code features. These include:

1. a problem designed to reproduce free-field fluences calculated by DORT,

2. a calculation of detector response- in a relatively small system called the "metric doghouse" (the reference DRC test case),

3. calculations of detector responses in two relatively large systems to examine the effects of inciuding $x-y$ dependence in the coupling calculation, and

4. a problem solvable by DORT involving the calculation of detector responses in a shielded, large-radius, annular, cylindrical tunnel in an air-over-ground radiation field.

For the latter calculation, the deterministic results from the DORT calculation can serve as a basis for checking the accuracy of the results from the coupled method.

\subsection{TEST PROBLEM 1: FREE-FIELD FLUENCE CALCULATION}

For this test problem, a 2-group DORT calculation is performed for a point source in air $300 \mathrm{~m}$ above a purely absorbing medium. Then an adjoint MASHX calculation is performed for a $1 \mathrm{~cm} \times 1 \mathrm{~cm} \times 50.5 \mathrm{~cm}$ air box over a purely absorbing medium ("ground") with the detector located at the $x-y$ center of the box $50 \mathrm{~cm}$ above "ground" [i.e. at the coordinate location $(100.0,0.0,50.0)$ ]. Coupling of the forward fluences with the adjoint leakages is performed with DRC2 and the results are compared with the free-field fluences also calculated by DRC2. Logarithmic interpolation of the VISTA fluences is used.

This problem is intended to demonstrate whether the coupled calculation reproduces the free-field fluences calculated by DORT. The DORT calculation file is shown in Fig. 1, the MASHX calculation file in Fig. 2, and the DRC2 calculation file in Fig. 3.

The DORT and DRC2 fluences are compared in Table 1 for 25,000 and 105,000 MASHX histories. For the two cases, the last six range/orientation combinations shown in Table 1 correspond to VISTA R-mesh locations and the detector is at a VISTA Z-mesh location. Hence, the free-field fluences should be calculated almost exactly at these range/orientations. The results show that the free-field fluences are reproduced within about $4 \%$. Also, since the system is very small in its $x$ and $y$ dimensions, the inclusion of $x-y$ fluence dependence in the coupling did not significantly influence the results. There is only the slightest variation due to the small distance of the escape surface from the detector point. 


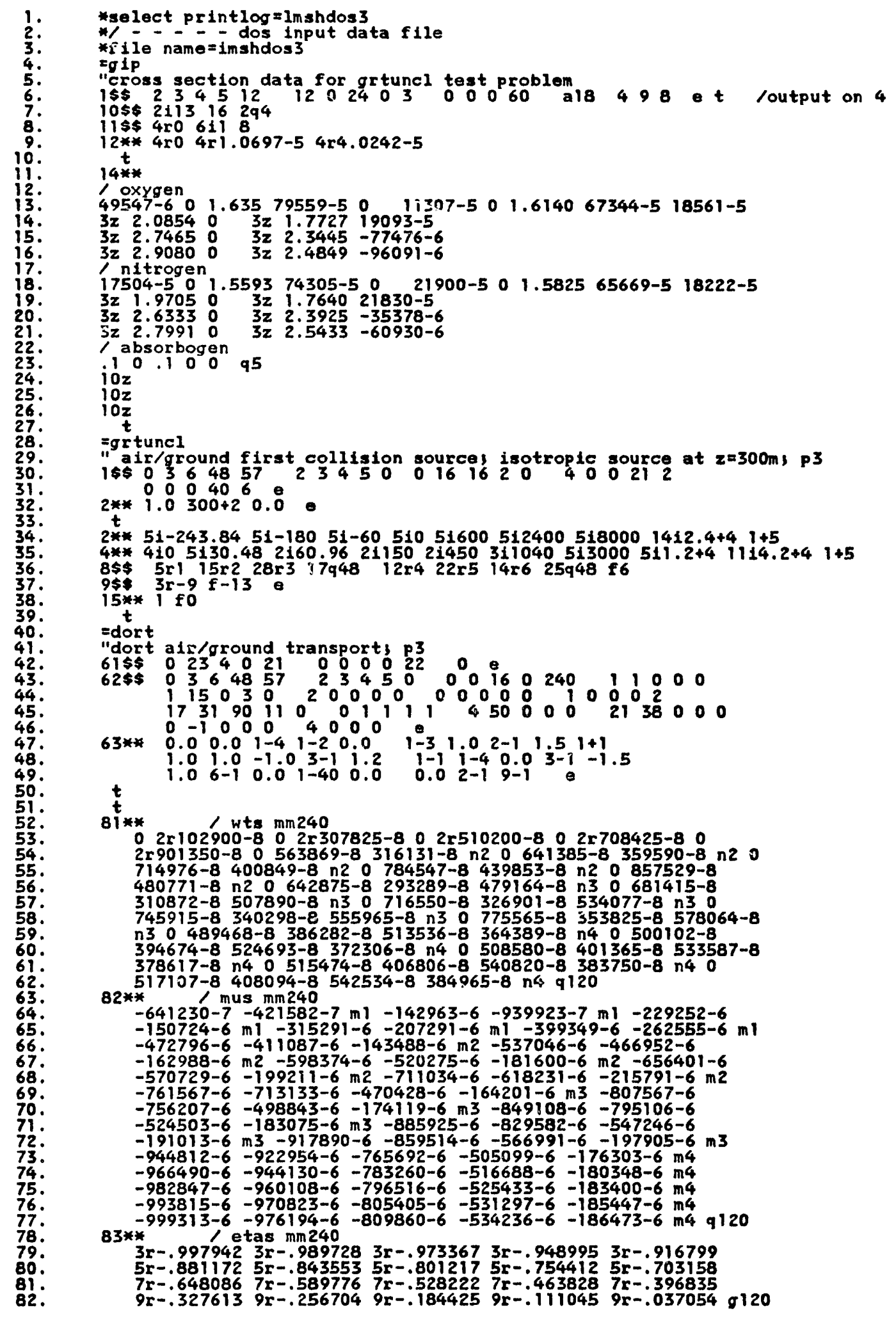

Fig. 1. GIP-GRTUNCL-DORT-VISTA Input for Test Problem 1: Free-Field Fluence Calculation. 


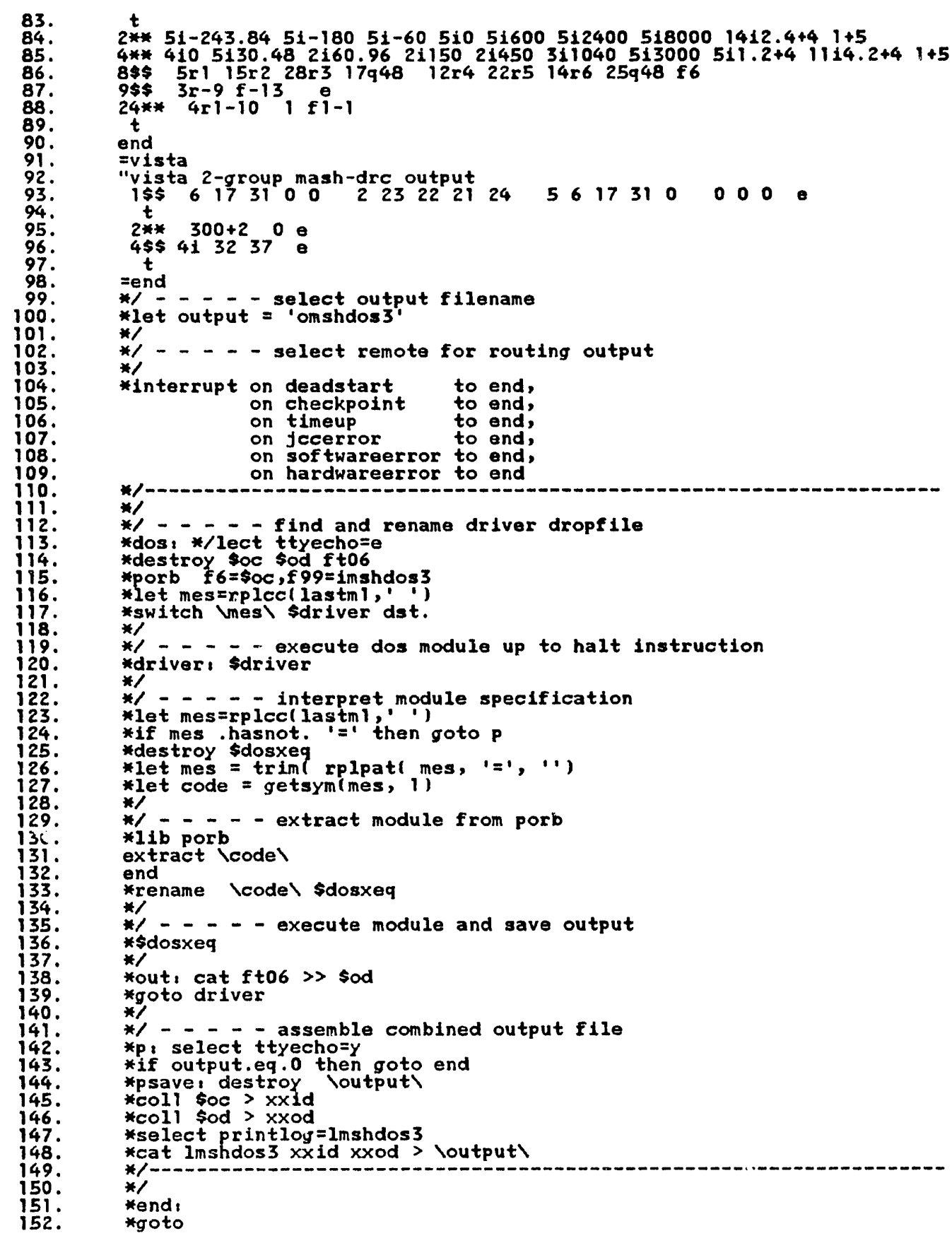

Fig. 1. (continued) 
L1sting For CRAY File "mshxo7"

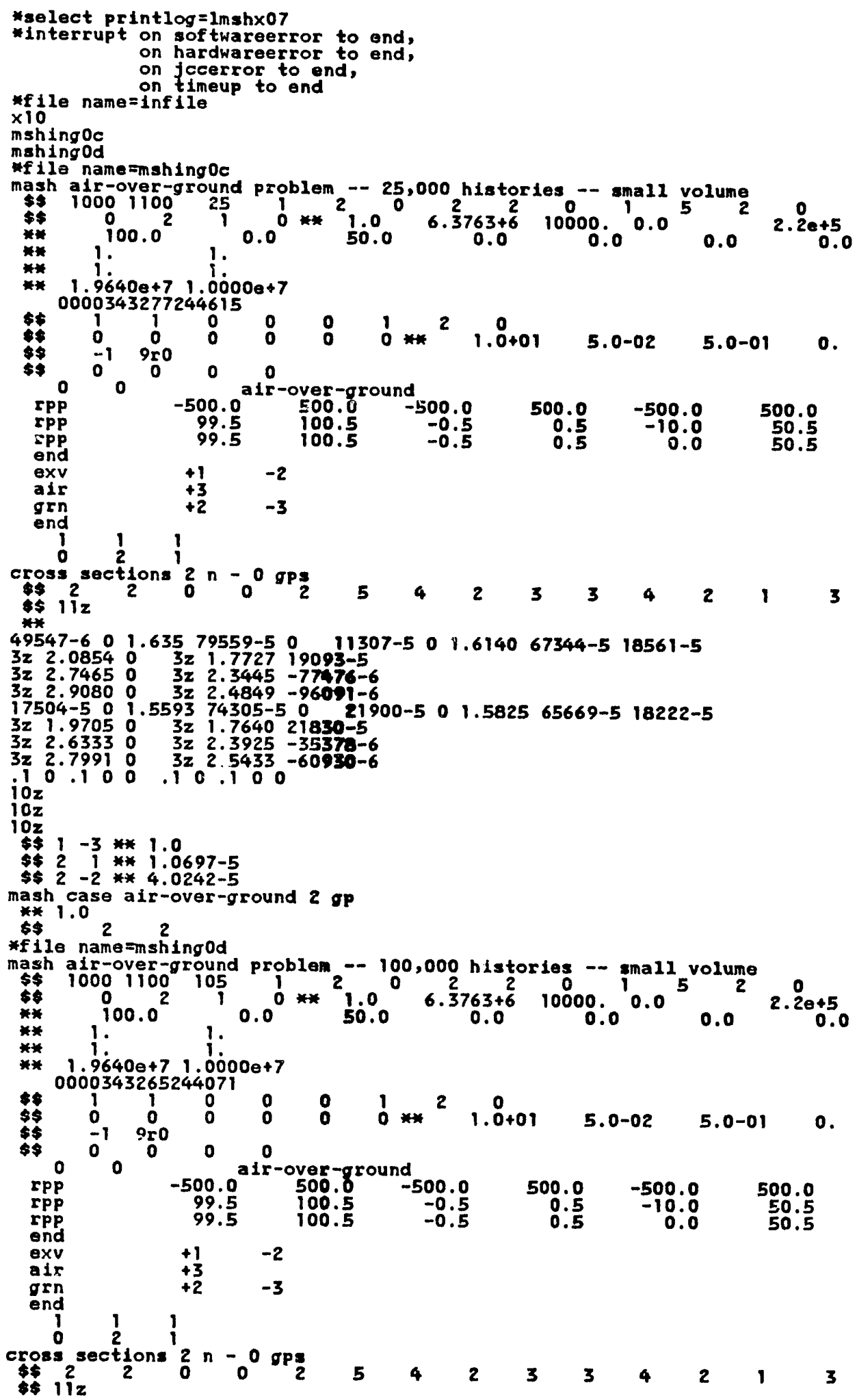

Fig. 2. MASHX Input for Test Problem 1: Free-Field Fluence Calculation. 


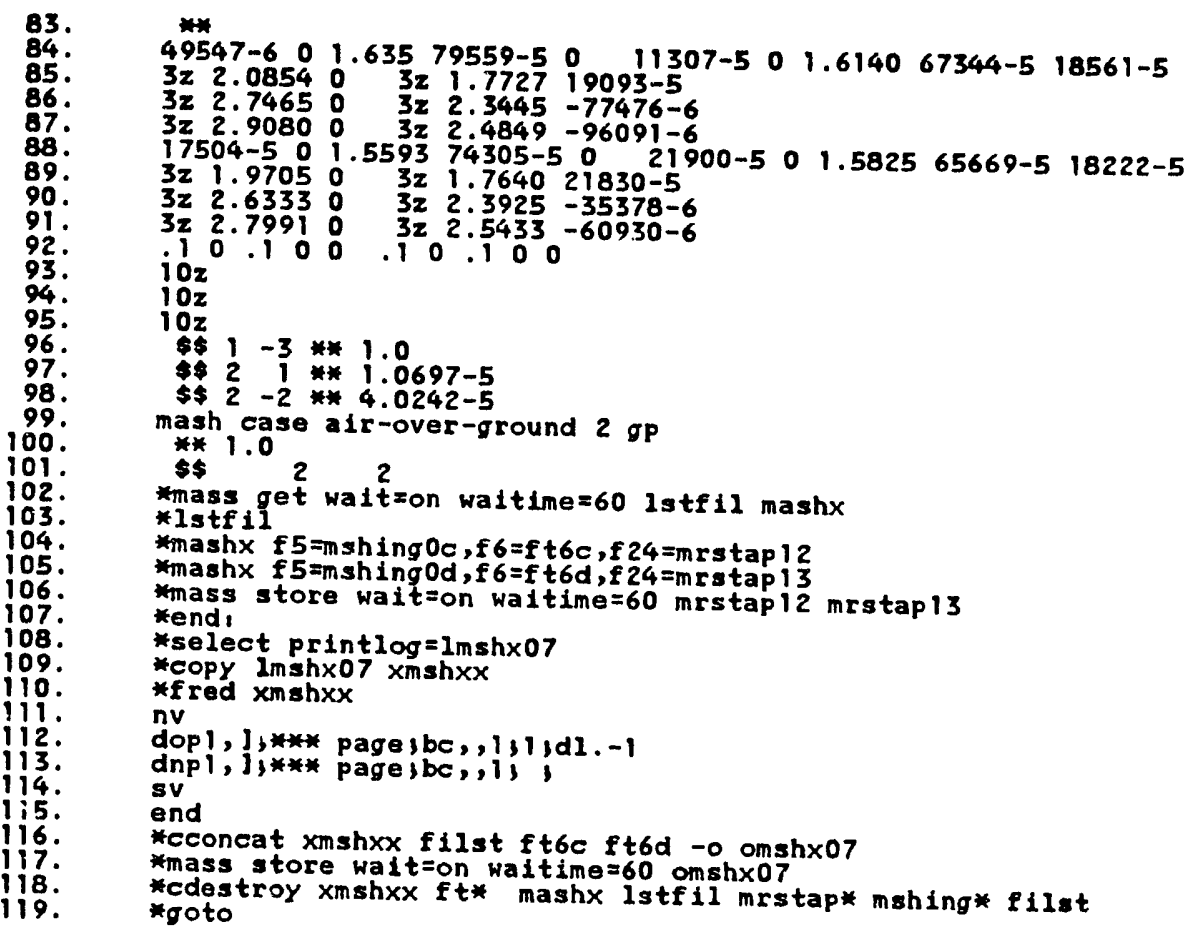

Fig. 2. (continued) 
Listing For CRAY File "dre2tle "

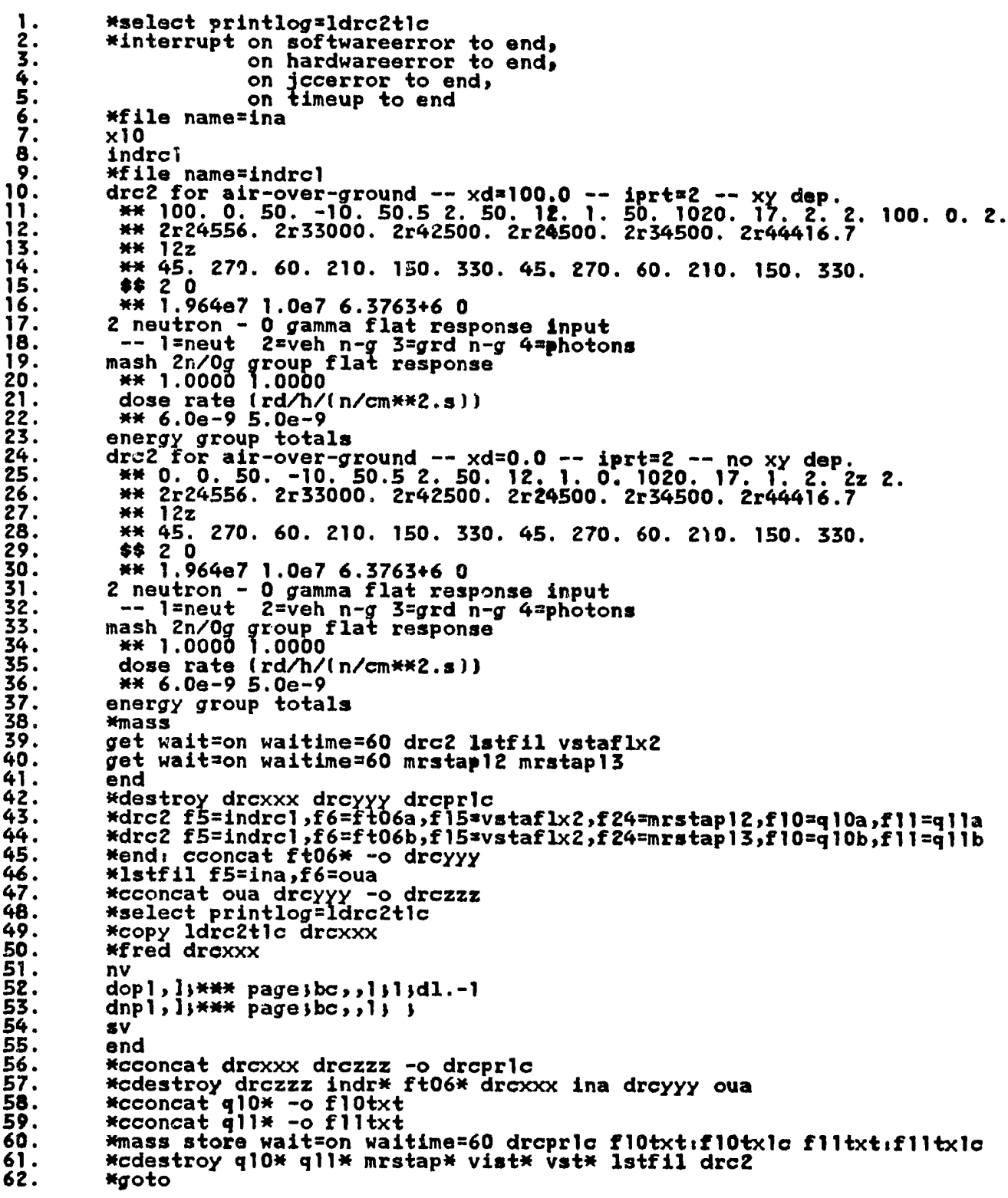

Fig. 3. DRC2 Input for Test Problem 1: Free-Field Fluence Calculation. 
Table 1. Comparison of DORT and DRC2 Calculated Fluences for Test Problem 1: Free-Field Fluence Calculation

\begin{tabular}{|c|c|c|c|}
\hline \multirow[b]{2}{*}{ Range (cm) } & \multirow[b]{2}{*}{$\begin{array}{c}\text { Orientation } \\
\text { (degrees) }\end{array}$} & \multicolumn{2}{|c|}{ DORT Fluence/DRC2 Fluence } \\
\hline & & $\begin{array}{l}\text { With No X-Y } \\
\text { Dependence }\end{array}$ & $\begin{array}{c}\text { With X-Y } \\
\text { Dependence }\end{array}$ \\
\hline \multicolumn{4}{|c|}{ Case 1 (240 Directions; 25,000 Histories) } \\
\hline 24556 & 45 & $0.999(.030)^{*}$ & $0.999(.030)$ \\
\hline 24556 & 270 & $1.009(.027)$ & $1.009(.027)$ \\
\hline 33000 & 60 & $1.008(.035)$ & $1.008(.035)$ \\
\hline 33000 & 210 & $1.036(.029)$ & $1.036(.029)$ \\
\hline 42500 & 150 & $0.994(.021)$ & $0.994(.021)$ \\
\hline 42500 & 330 & $1.040(.018)$ & $1.040(.018)$ \\
\hline 24500 & 45 & $0.999(.030)$ & $0.999(.030)$ \\
\hline 24500 & 270 & $1.009(.027)$ & $1.009(.027)$ \\
\hline 34500 & 60 & $1.004(.034)$ & $1.004(.034)$ \\
\hline 34500 & 210 & $1.032(.029)$ & $1.032(.029)$ \\
\hline 44417 & 150 & $0.960(.024)$ & $0.960(.024)$ \\
\hline 44417 & 330 & $1.008(.020)$ & $1.008(.020)$ \\
\hline \multicolumn{4}{|c|}{ Case 2 (240 Directions; 105,000 Histories) } \\
\hline 24556 & 45 & $1.001(.014)$ & $1.001(.014)$ \\
\hline 24556 & 270 & $1.021(.013)$ & $1.021(.013)$ \\
\hline 33000 & 60 & $1.003(.012)$ & $1.003(.012)$ \\
\hline 33000 & 210 & $1.011(.013)$ & $1.011(.013)$ \\
\hline 42500 & 150 & $1.037(.011)$ & $1.037(.011)$ \\
\hline 42500 & 330 & $1.020(.010)$ & $1.020(.010)$ \\
\hline 24500 & 45 & $1.000(.014)$ & $1.000(.014)$ \\
\hline 24500 & 270 & $1.021(.013)$ & $1.021(.013)$ \\
\hline 34500 & 60 & $0.998(.012)$ & $0.998(.012)$ \\
\hline 34500 & 210 & $1.007(.013)$ & $1.007(.013)$ \\
\hline 44417 & 150 & $1.010(.011)$ & $1.010(.011)$ \\
\hline 44417 & 330 & $0.993(.011)$ & $0.993(.011)$ \\
\hline
\end{tabular}

*Fractional standard deviations are shown in parentheses. 
The agreement of the coupled results with the DORT free-field results did not improve with the increased number of histories. However, as noted in Table 1, the fractional standard deviations (fsd's) of the results were cut in half in most cases from the range $0.018-0.035$ to the range $0.010-0.014$. The DRC2 results generally fall within three fsd's about the DORT results.

There were only two scatterings in the air in the small box for the 25,000 history case and only one for the 105,000 history case. The scatterings were undersampled, but those few scatterings should not have contributed much to the fluence, since scatterings below the detector point must direct the neutron upward for it to contribute significantly (the upward-directed angular fluence in the air from 0 to $50 \mathrm{~cm}$ above the purely absorbing medium should be much smaller than the downwarddirected angular fluence).

Sonie printed output pages from this test problem are shown in the Appendix.

\subsection{TEST PROBLEM 2: METRIC DOGHOUSE}

The second test case is a two-group calculation of detector responses within a $3 \mathrm{~m} \times 1 \mathrm{~m} \times 1 \mathrm{~m}$ building with 5 -cm-thick side walls ard a 10 -cm-thick roof all composed of purely absorbing material and a $1 \mathrm{~m}$-wide doorway along and at one end of the $3 \mathrm{~m}$ wall ( $\mathrm{X}$ dimension). A drawing of the building is shown in Fig. 4 . The detector is centered on the doorway and at the $\mathrm{Y}$ center of the room. This problem was calculated mainly to compare results with those obtained with DRC for this same test problem. The DORT calculation file is shown in Fig. 5, the MASHX calculation file* in Fig. 6, and the DRC2 calculation file in Fig. 7. The DORT calculation used a 30 direction quadrature set $\left(S_{6}\right)$ and a $P_{3}$ cross-section Legendre expansion. For this problem, the coupling surface is at the outside of the building. Rigorous calculations using forward and adjoint coupling require that the coupling surface be located at such a distance from the object (building, vehicle, etc.) that there is no significant perturbation of the free-field fluence by the object. In practice, if the object is small, the coupling surface may be located very close to the object. The effect the metric doghouse, with its purely absorbing walls, has on the inward-directed free-field fluences at the house outer surface is not known. Certainly, fluences incident on surfaces hidden from direct view of the source will be perturbed. The contributions of those fluences to the calculated response may be small, however, because the fluences are basically forward peaked.

Protection factors calculated by DRC2 are compared in Table 2 for coupling with and without $\mathrm{x}-\mathrm{y}$ dependent forward fluences and both without and with in-group biasing (INGB $=0$ or 1 , respectively). It is noted that for this small system, $x-y$ depentent coupling influenced the answers very little. A greater difference is shown

* This file also contains input for an air-over-ground free-field fluence calculation using a larger air box than that used in Test Problem 1. Results from this calculation were superseded by those reported in Test Problem 1 (Section 6.1). 


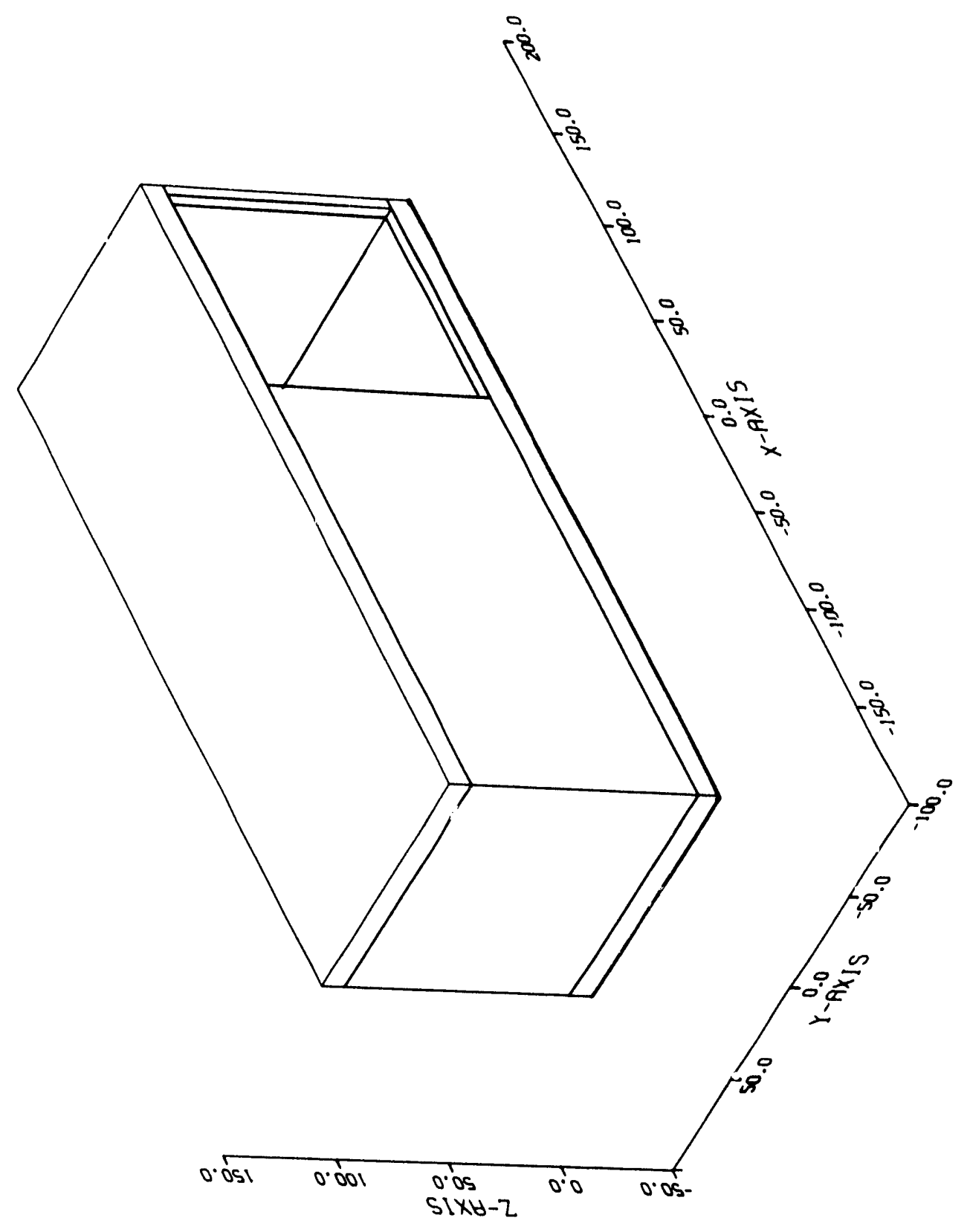

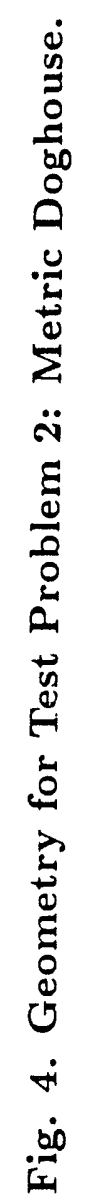




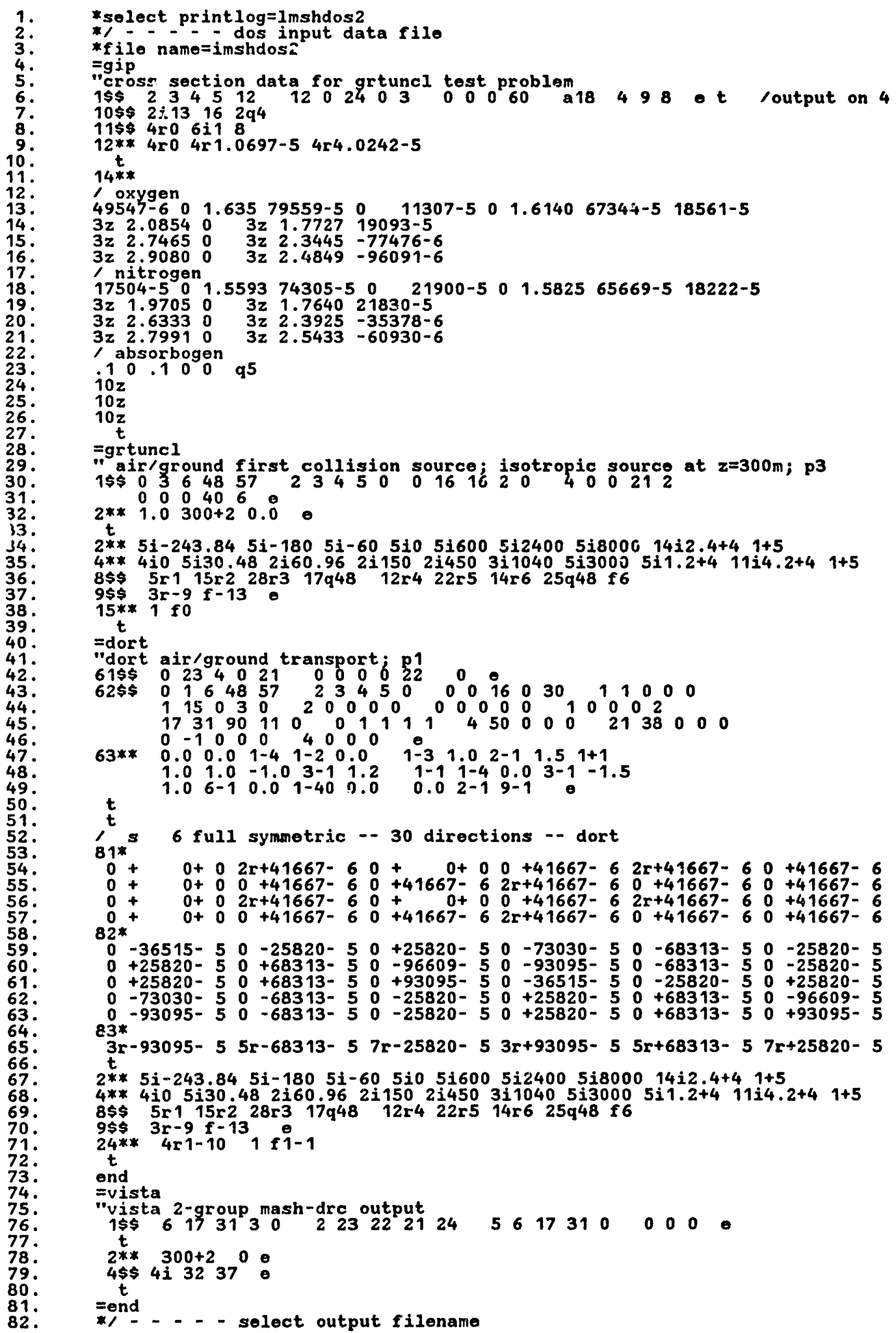

Fig. 5. GIP-GRTUNCL-DORT-VISTA Input for Test Problem 2: Metric Doghouse. 


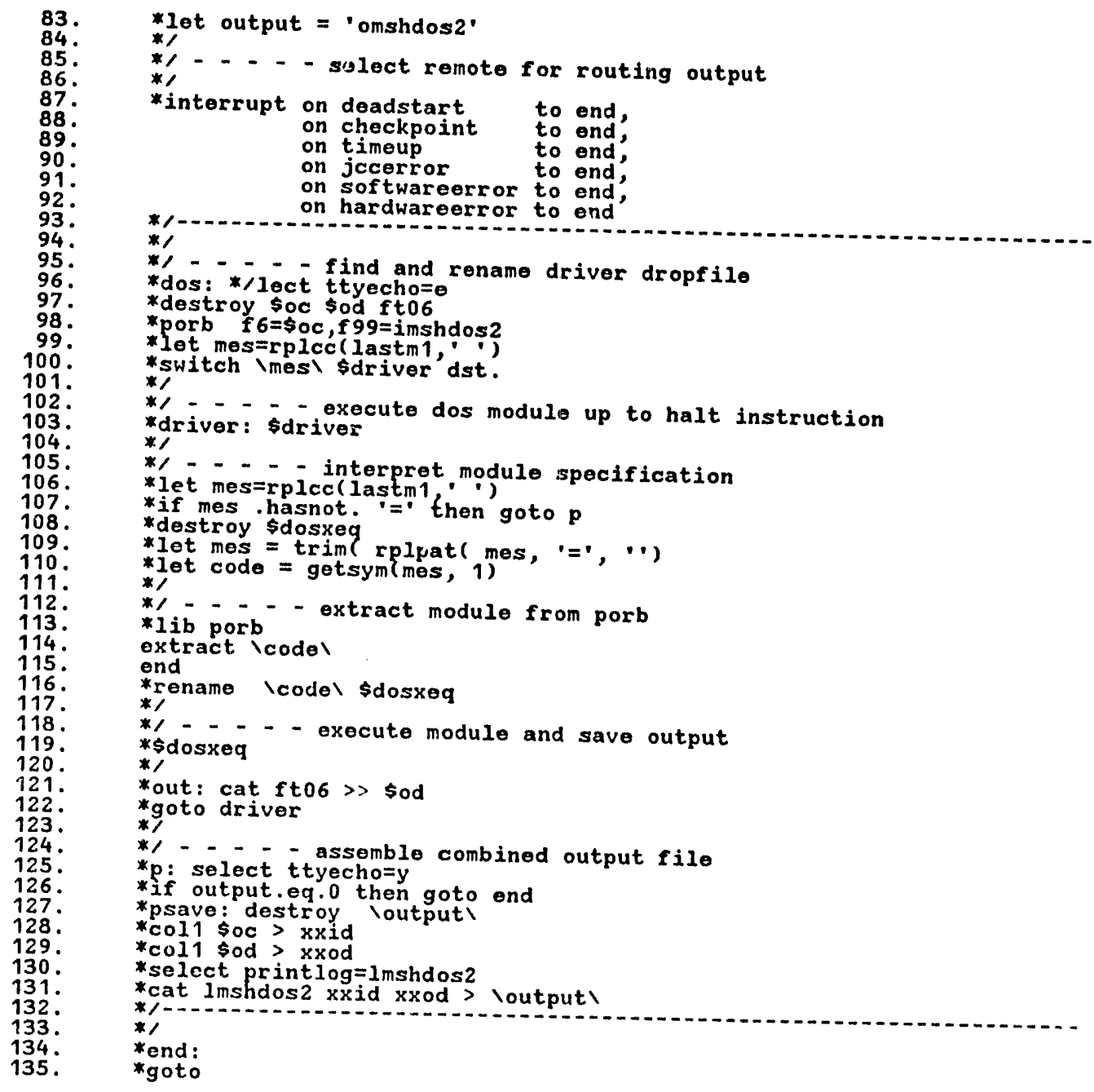

Fig. 5. (continued) 
Listing For CRAY File "mshx1 "

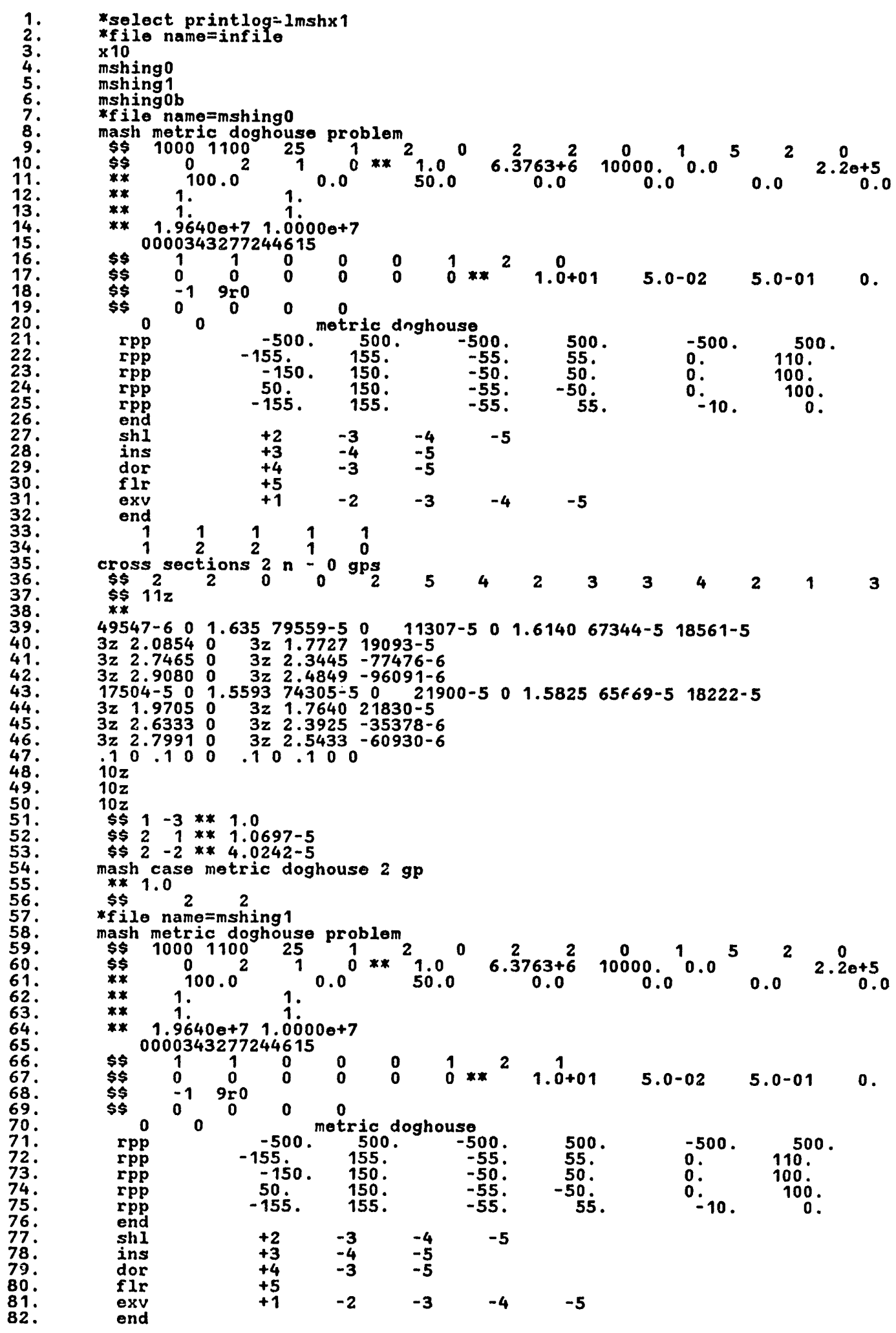

Fig. 6. MASHX Input for Test Problem 2: Metric Doghouse. 


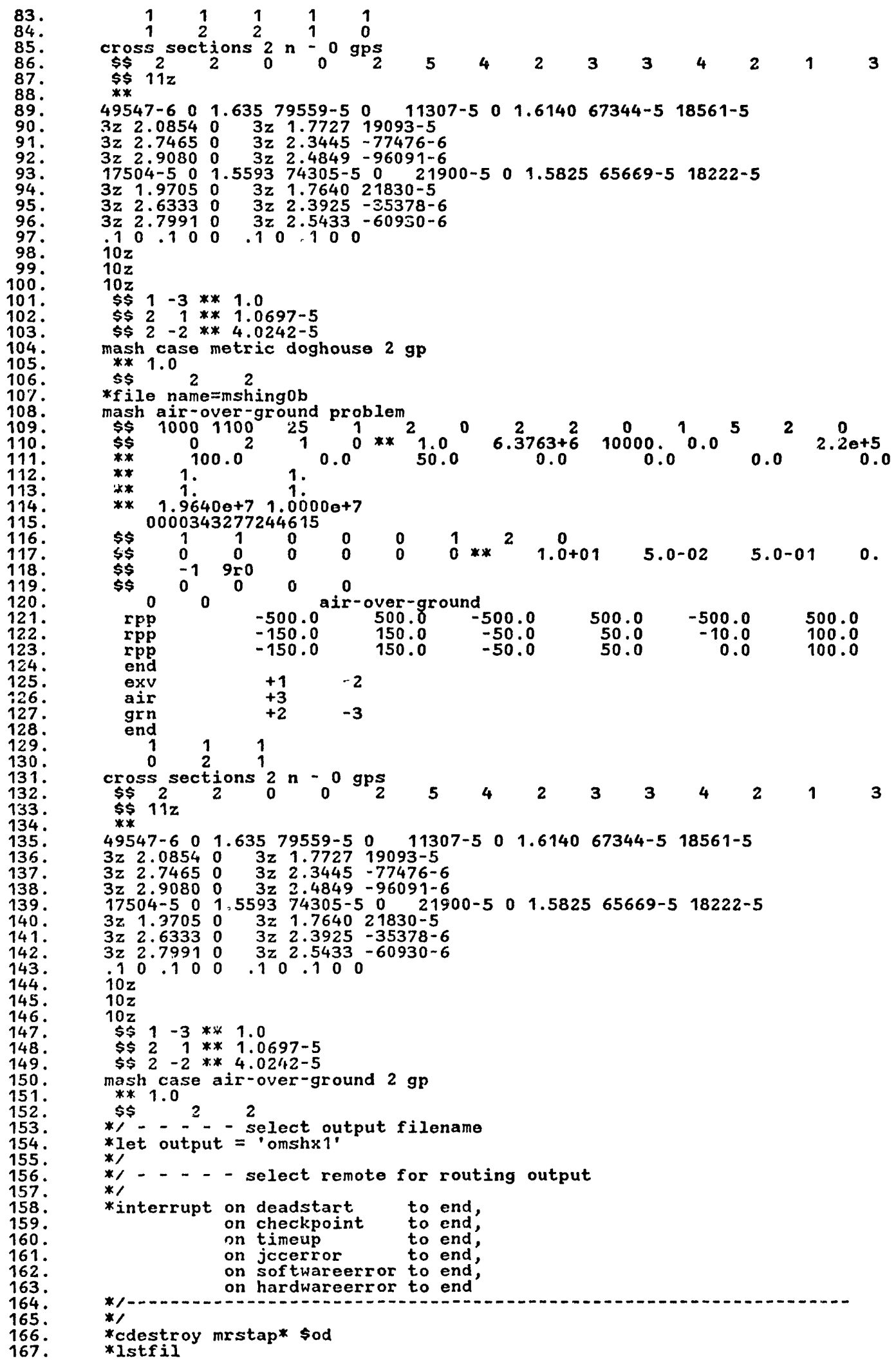

Fig. 6. (continued) 


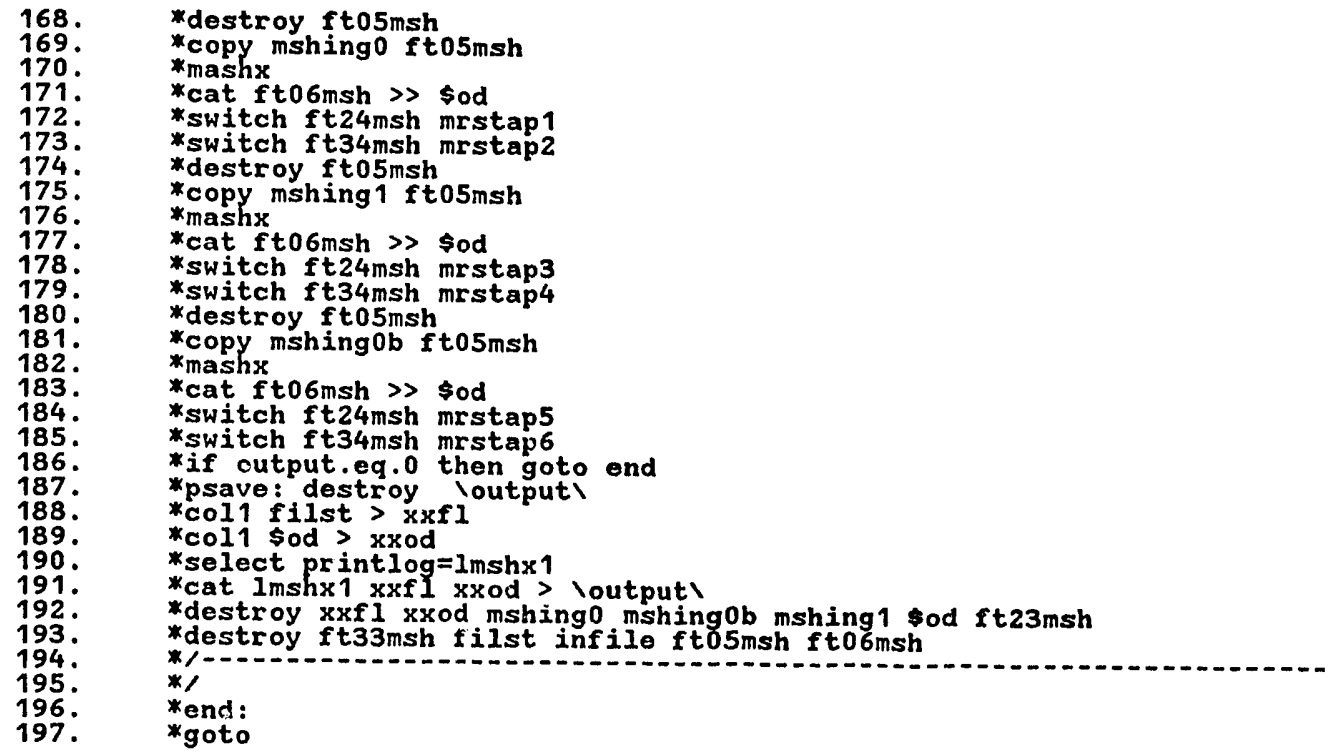

Fig. 6. (continued) 
Listing For CRAY File "dre2tlx"

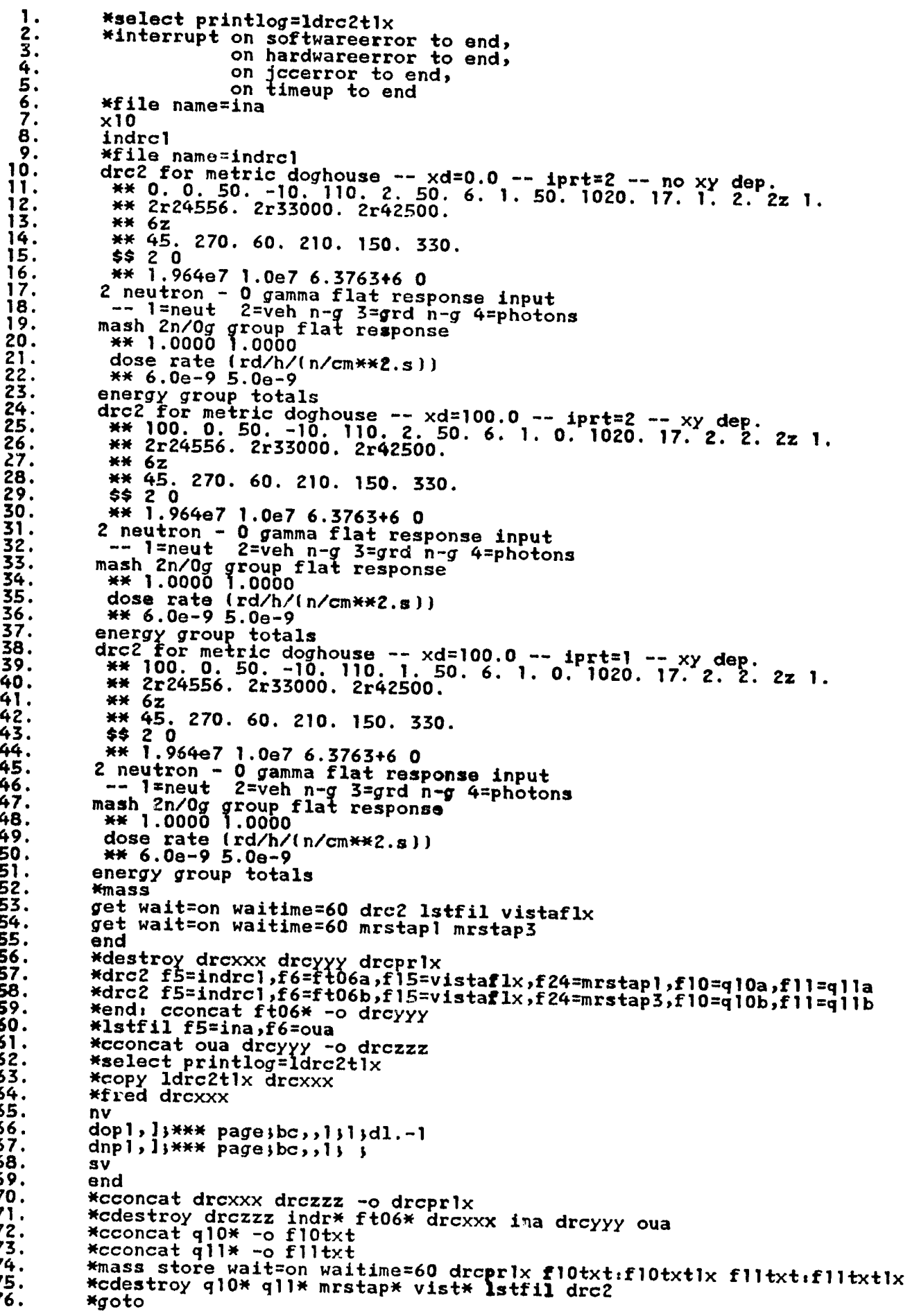

Fig. 7. DRC2 Input for Test Problem 2: Metric Doghouse. 
Table 2. Comparison of DRC2 Calculated Protection Factors for Test Problem 2:

Metric Doghouse

\begin{tabular}{|c|c|c|c|c|}
\hline \multirow[b]{2}{*}{ Range (cm) } & \multirow[b]{2}{*}{$\begin{array}{c}\text { Orientation } \\
\text { (degrees) }\end{array}$} & \multicolumn{2}{|c|}{ DRC2 Protection Factors } & \multirow[b]{2}{*}{$\%$ Difference } \\
\hline & & $\begin{array}{l}\text { With No X-Y } \\
\text { Dependence }\end{array}$ & $\begin{array}{c}\text { With X-Y } \\
\text { Dependence }\end{array}$ & \\
\hline \multicolumn{5}{|c|}{ Case $1($ INGB $=0)$} \\
\hline $\begin{array}{l}24556 \\
24556 \\
33000 \\
33000 \\
42500 \\
42500\end{array}$ & $\begin{array}{r}45 \\
270 \\
60 \\
210 \\
150 \\
330\end{array}$ & $\begin{array}{l}2.715 \\
1.912^{* *} \\
2.576 \\
2.104 \\
2.261 \\
2.373\end{array}$ & $\begin{array}{l}2.718 \\
1.908 \\
2.574 \\
2.104 \\
2.258 \\
2.368\end{array}$ & $\begin{array}{c}0.11 \\
-0.21 \\
-0.08 \\
- \\
-0.13 \\
-0.21\end{array}$ \\
\hline \multicolumn{5}{|c|}{ Case $2($ INGB $=1)$} \\
\hline $\begin{array}{l}24556 \\
24556 \\
33000 \\
33000 \\
42500 \\
42500\end{array}$ & $\begin{array}{r}45 \\
270 \\
60 \\
210 \\
150 \\
330\end{array}$ & $\begin{array}{l}2.798 \\
1.883^{* * *} \\
2.643 \\
2.062 \\
2.302 \\
2.375\end{array}$ & $\begin{array}{l}2.797 \\
1.880 \\
2.642 \\
2.060 \\
2.298 \\
2.371\end{array}$ & $\begin{array}{l}-0.04 \\
-0.16 \\
-0.04 \\
-0.10 \\
-0.17 \\
-0.17\end{array}$ \\
\hline
\end{tabular}

$*\left(\frac{x-y \text { dep }}{\text { no } x-y \text { dep }}-1\right) \times 100$.

**DRC calculated a protection factor of 1.913.

***DRC calculated a protection factor of 1.884 . 
between results without in-group biasing and those with in-group biasing. Also note that $\mathrm{DRC}$ gave essentially the same result as the no $\mathrm{X}-\mathrm{Y}$ dependence $\mathrm{DRC} 2$ at the one point indicated in Table 2, differing by only $0.05 \%$ for both INGB $=0$ and $\mathrm{INGB}=1$. Fractional standard deviations ranged from 0.015 to 0.029 .

\subsection{TEST PROBLEM 3: LARGE $(30 M \times 6 M \times 3 M)$ STEEL-TOPPED CONCRETE BUILDING}

The third test case is a 69-group (46 neutron and 23 gamma-ray) calculation of detector responses in a large ( $30 \mathrm{~m}$ long by $6 \mathrm{~m}$ wide by $3 \mathrm{~m}$ high) steel-topped concrete building. The side walls of the building are $20 \mathrm{~cm}$ thick and are composed of ordinary concrete. The floor is a 10 -cm-thick slab of borated concrete and the roof is a 10-cm-thick steel slab. There are two doorways, two windows, an interior partial concrete wall, and an opening in the roof. Drawings of the building are shown in Figs. 8 and 9. Fig. 9, with the roof removed, shows the interior of the building. The detector position is near a window and the interior partial wall so that it may be shielded by the wall or exposed by the window or the roof opening, depending on the orientation. The system rotation point is at $\mathrm{x}=1500 \mathrm{~cm}$ and $\mathrm{y}=300 \mathrm{~cm}$.

This problem is intended to test the effects on calculated responses of including $x-y$ dependence in the coupling calculation. While the building may occupy only one DORT radial mesh interval or portions of two, the variation of the fluence across the expanse of the building could be significant.

The source for the calculation is a point source at zero radius and $300 \mathrm{~m}$ above the ground. It consists of prompt neutron and gamma-ray fission sources obtained by extrapolating and regrouping data from Ref. 6 and combining without regard to normalization except that all values were multiplied by $10^{15}$. The tissue dose response function was obtained from the $\mathrm{DABL} 69^{7}$ response function set. A 240 direction quadrature set and the DABL69 cross section library with a $\mathrm{P}_{5}$ Legendre expansion were used.

Table 3 is a comparison of neutron and gamma-ray tissue dose protection factors calculated with DRC2 using $x-y$ dependent coupling with those calculated by DRC2 using no $x y$ dependent coupling. At close range $(26.73 \mathrm{~m})$ and an orientation $(172.5$ deg.) where the detector position is partially exposed due to the roof opening, the neutron and gamma-ray protection factors calculated with $x-y$ dependent coupling show a greater than $10 \%$ difference from the result with no $x-y$ dependent coupling. At distant ranges, the $180 \mathrm{deg}$. orientation gives the largest differences in the protection factors, probably because of the exposure provided by the roof opening. Although the neutron protection factors differ by less than $5 \%$, the gainma-ray protection factors at two range/orientations differ by greater than $10 \%$.

Even though differences in neutron protection factors were less than $5 \%$ at distant ranges, Table 4 shows that the calculated neutron doses can differ by greater amounts. The protection factors tend to differ less than the fluences or doses be- 

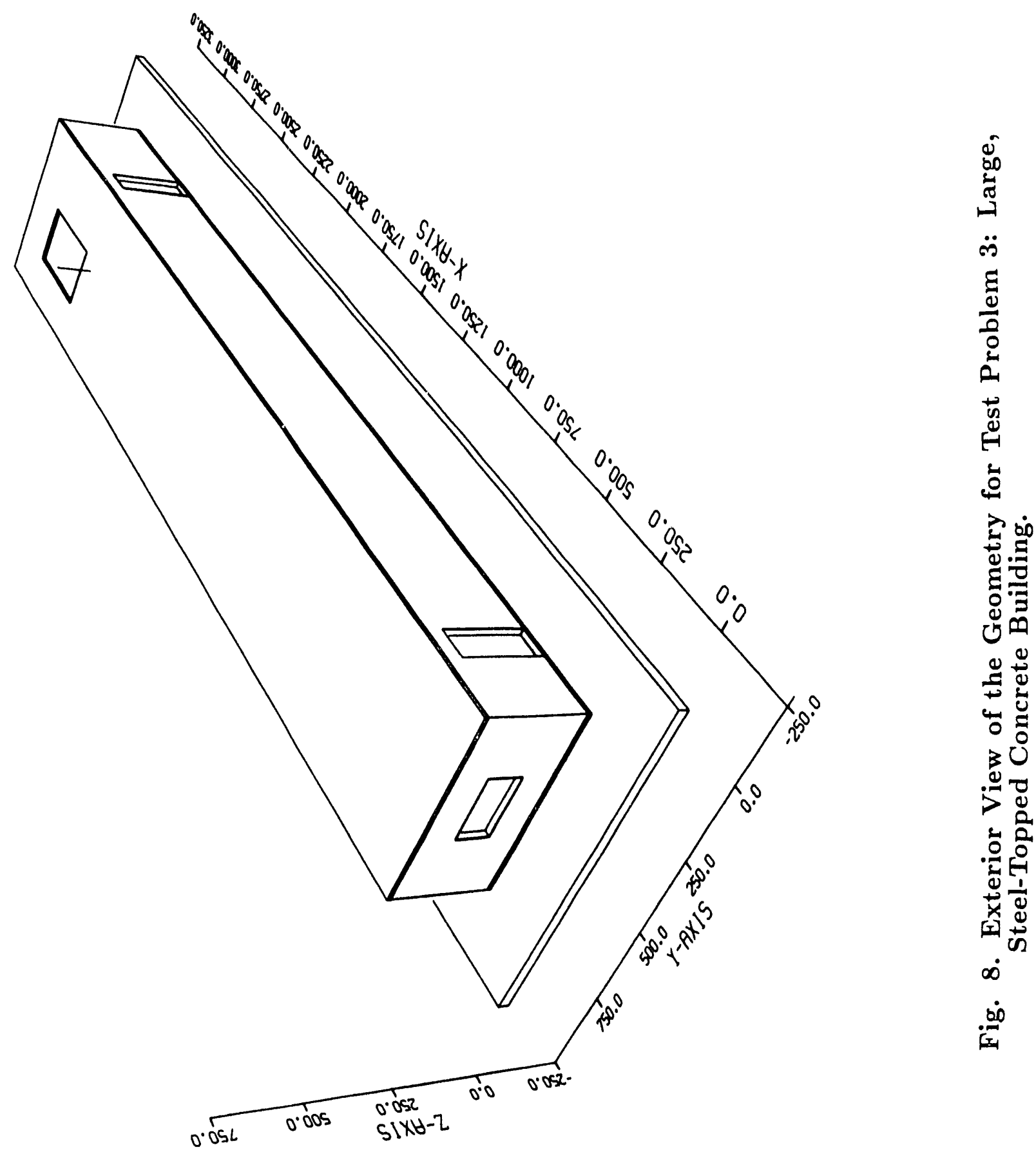


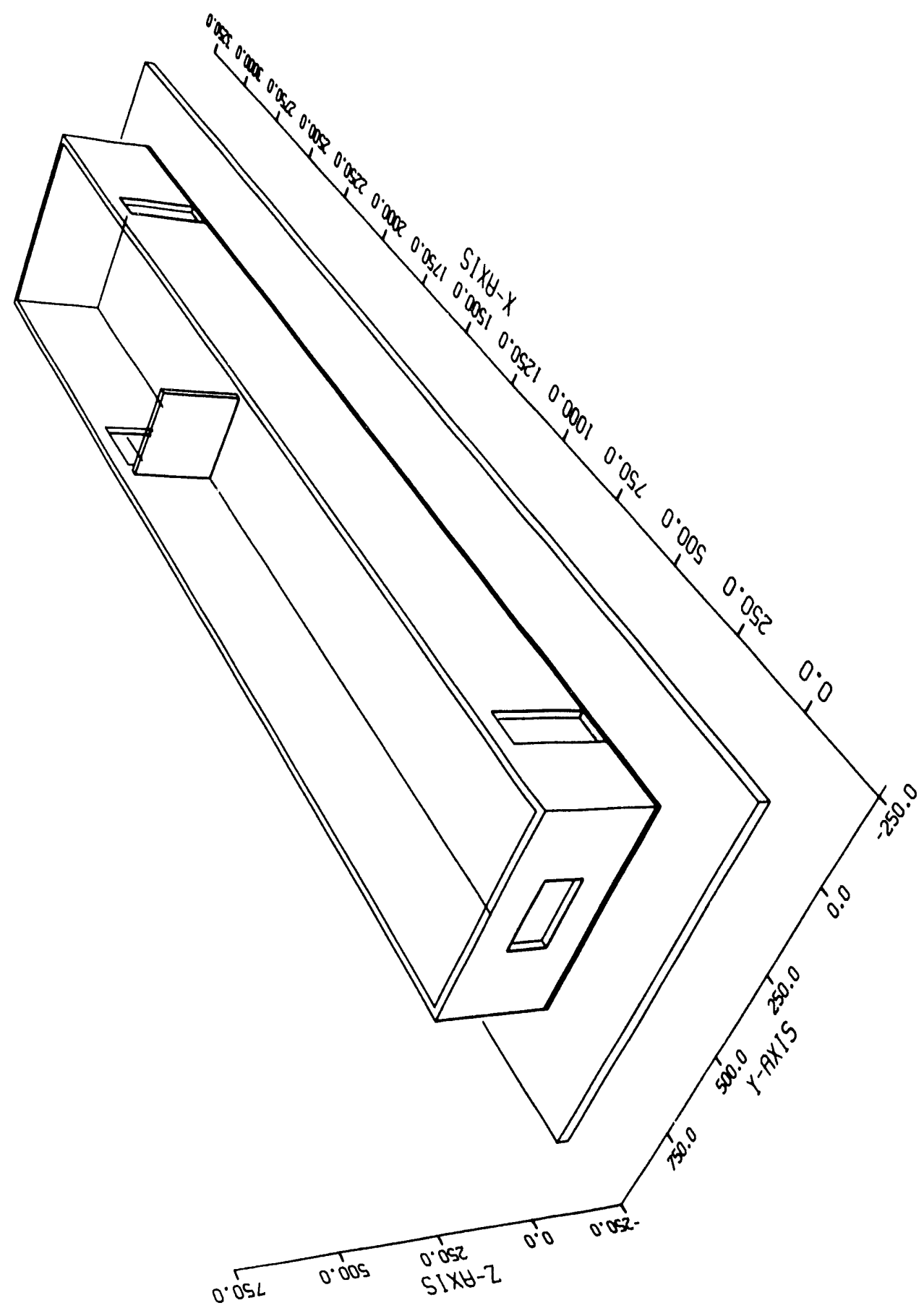

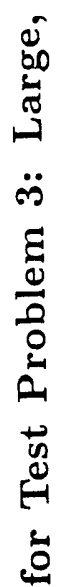

要

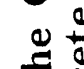

के

30

$j$

.

웅

岂

$\dot{0}^{\circ}$

$\stackrel{00}{10}$ 
Table 3. Comparison of DRC2 Calculated Neutron and Gamma-Ray Tissue Dose Protection Factors for Test Problem 3: Large Steel-Topped Concrete Building

\begin{tabular}{|c|c|c|c|c|}
\hline \multirow[b]{2}{*}{ Range (m) } & \multirow[b]{2}{*}{$\begin{array}{c}\text { Orientation } \\
\text { (degrees) }\end{array}$} & \multicolumn{2}{|c|}{ Protection Factors (tissue dose) } & \multirow[b]{2}{*}{$\%$ Difference* } \\
\hline & & $\begin{array}{c}\text { With No X-Y } \\
\text { Dependence }\end{array}$ & $\begin{array}{c}\text { With X-Y } \\
\text { Dependence }\end{array}$ & \\
\hline \multicolumn{5}{|c|}{ Neutron } \\
\hline $\begin{array}{c}26.73 \\
26.73 \\
150 \\
150 \\
150 \\
150 \\
300 \\
300 \\
300 \\
300\end{array}$ & $\begin{array}{r}0 \\
172.5 \\
0 \\
90 \\
180 \\
270 \\
0 \\
90 \\
180 \\
270\end{array}$ & $\begin{array}{l}2.997 \\
2.700 \\
4.077 \\
2.769 \\
3.194 \\
3.797 \\
4.026 \\
2.422 \\
3.088 \\
3.624\end{array}$ & $\begin{array}{l}2.774 \\
2.986 \\
4.131 \\
2.792 \\
3.127 \\
3.821 \\
4.090 \\
2.399 \\
2.939 \\
3.588\end{array}$ & $\begin{array}{c}-7.44 \\
10.6 \\
1.32 \\
0.83 \\
-2.1 \\
0.63 \\
1.59 \\
-0.95 \\
-4.83 \\
-0.99\end{array}$ \\
\hline \multicolumn{5}{|c|}{ Gamma Ray } \\
\hline $\begin{array}{c}26.73 \\
26.73 \\
150 \\
150 \\
150 \\
150 \\
300 \\
300 \\
300 \\
300\end{array}$ & $\begin{array}{c}0 \\
172.5 \\
0 \\
90 \\
180 \\
270 \\
0 \\
90 \\
180 \\
270\end{array}$ & $\begin{array}{c}39.41 \\
21.33 \\
36.53 \\
12.60 \\
16.27 \\
25.79 \\
33.33 \\
6.630 \\
13.45 \\
16.04\end{array}$ & $\begin{array}{c}39.88 \\
26.48 \\
37.46 \\
13.39 \\
18.30 \\
25.90 \\
34.07 \\
6.742 \\
12.04 \\
15.56\end{array}$ & $\begin{array}{c}1.19 \\
24.1 \\
2.55 \\
6.27 \\
12.5 \\
0.43 \\
2.22 \\
1.69 \\
-10.5 \\
-2.99\end{array}$ \\
\hline
\end{tabular}


Table 4. Comparison of DRC2 Calculated Neutron Tissue Dose for Test Problem 3: Large Steel-Topped Concrete Building

\begin{tabular}{ccccc}
\hline & \multicolumn{3}{c}{ Neutron Tissue Dose* } & \\
\cline { 3 - 4 } Range $(\mathrm{cm})$ & $\begin{array}{c}\text { Orientation } \\
\text { (degrees) }\end{array}$ & $\begin{array}{c}\text { With No X-Y } \\
\text { Dependence }\end{array}$ & $\begin{array}{c}\text { With X-Y } \\
\text { Dependence }\end{array}$ & \% Difference** \\
\hline 26.73 & 0 & $4.035-2^{* * *}$ & $4.157-2$ & 3.02 \\
26.73 & 172.5 & $4.475-2$ & $4.215-2$ & -5.81 \\
150 & 0 & $5.297-3$ & $4.822-3$ & 8.97 \\
150 & 90 & $8.123-3$ & $8.081-3$ & -0.52 \\
150 & 180 & $6.966-3$ & $7.702-3$ & 10.6 \\
150 & 270 & $5.757-3$ & $5.673-3$ & -1.46 \\
300 & 0 & $8.580-4$ & $7.918-4$ & -7.72 \\
300 & 90 & $1.517-3$ & $1.539-3$ & 1.45 \\
300 & 180 & $1.164-3$ & $1.308-3$ & 12.4 \\
300 & 270 & $9.742-4$ & $9.790-4$ & 0.49 \\
\hline
\end{tabular}

${ }^{*}$ The free-field doses are $1.323-1,2.499-2$, and $4.079-3$ at $26.73 \mathrm{~m}, 150 \mathrm{~m}$, and $300 \mathrm{~m}$, respectively. With the detector located about $550 \mathrm{~cm}$ from the vehicle system rotation point, the $x-y$ dependent free-field dose varies from $7.6 \%$ below to $8.2 \%$ above the reference values, the largest variations being for 0 - and 180-degree rotations.

** $\left(\frac{\mathrm{x}-\mathrm{y} \text { dep }}{\text { no } \mathbf{x}-\mathrm{y} \text { dep }}-1\right) \times 100$.

$* * * \operatorname{Read}$ as $4.035 \times 10^{-2}$. 
cause the division of the free-field quantities by the shielded quantities cancels crrors in both quantities, particularly when there is not much spectral shift in the important energy regions. Fractional standard deviations of the cited results are in the range 0.027 to 0.059 with $x-y$ dependent coupling and 0.027 to 0.049 without $x-y$ dependent coupling.

\subsection{TEST PROBLEM 4: BREN SIX-HOUSE CLUSTER}

The fourth test case involves the calculation of neutron and gamma-ray dose rates and protection factors at a detector location within a BREN six-house cluster. A picture of the cluster (from Ref. 8) is shown in Fig. 10. A plan view of the cluster is shown in Fig. 11. The detector locations identified on the figure have no meaning for this test problem. The box enclosing the local system geometry is about $25.4 \mathrm{~m}$ $\times 25.3 \mathrm{~m} \times 10.2 \mathrm{~m}$. Overall, this system is larger than that for test problem 3. However, because VISTA fluences were available for only four radial locations and these were 300 to $500 \mathrm{~m}$ apart, the entire system can fit within one interval between the VISTA fluence points (The fluences were obtained from a file created by W. A. Rhoades). The ranges were chosen at the VISTA fluence locations; hence for a given range, the calculated fluences incident on the system may involve up to three of the VISTA fluence radial points in the interpolation of the fluences. Logarithmic interpolation of the fluences was used.

For a rotation point at the center of the system, the surface points are removed from the VISTA fluence points by at most about $6 \%$ of the distance between adjacent points. Thus, the $\mathrm{x}-\mathrm{y}$ dependent fluence values should be 94 to $100 \%$ of the VISTA fluence values when linear interpolation is used and one could expect little difference between results obtained with $x-y$ dependent coupling and those obtained with no $x-y$ dependent coupling. For the fluence differences over the given ranges, logarithmic interpolation should also show small differences between the $x-y$ dependent and the no $x-y$ dependent results.

Table 5 compares soft tissue kerma total protection factors calculated by DRC2 using $\mathrm{x}-\mathrm{y}$ dependence in the coupling operation to those calculated by DRC2 without using $x-y$ dependence in the coupling operation. All differences are essentially $3 \%$ or less. Table 6 compares DRC and DRC2 calculated soft tissue kerma total protection factors. Differences less than $3 \%$ are observed here also. Finally, Table 7 compares DRC and DRC2 calculated soft tissue kerma values. The differences are generally larger than those observed for the protection factors, but they fall within the $6 \%$ variation in the incident fluence over the surface of the system mentioned above. With no $x-y$ dependent coupling, DRC2 gives the same results as DRC. Fractional standard deviations of tcital quantities ranged from about 0.01 to 0.06 . The uncertainties associated with the dose due to capture gamma rays in the houses were generally greater than $30 \%$.

A computation charge comparison between DRC and DRC2 was also made for this test problem. A separate DRC calculation was performed for each range, but 


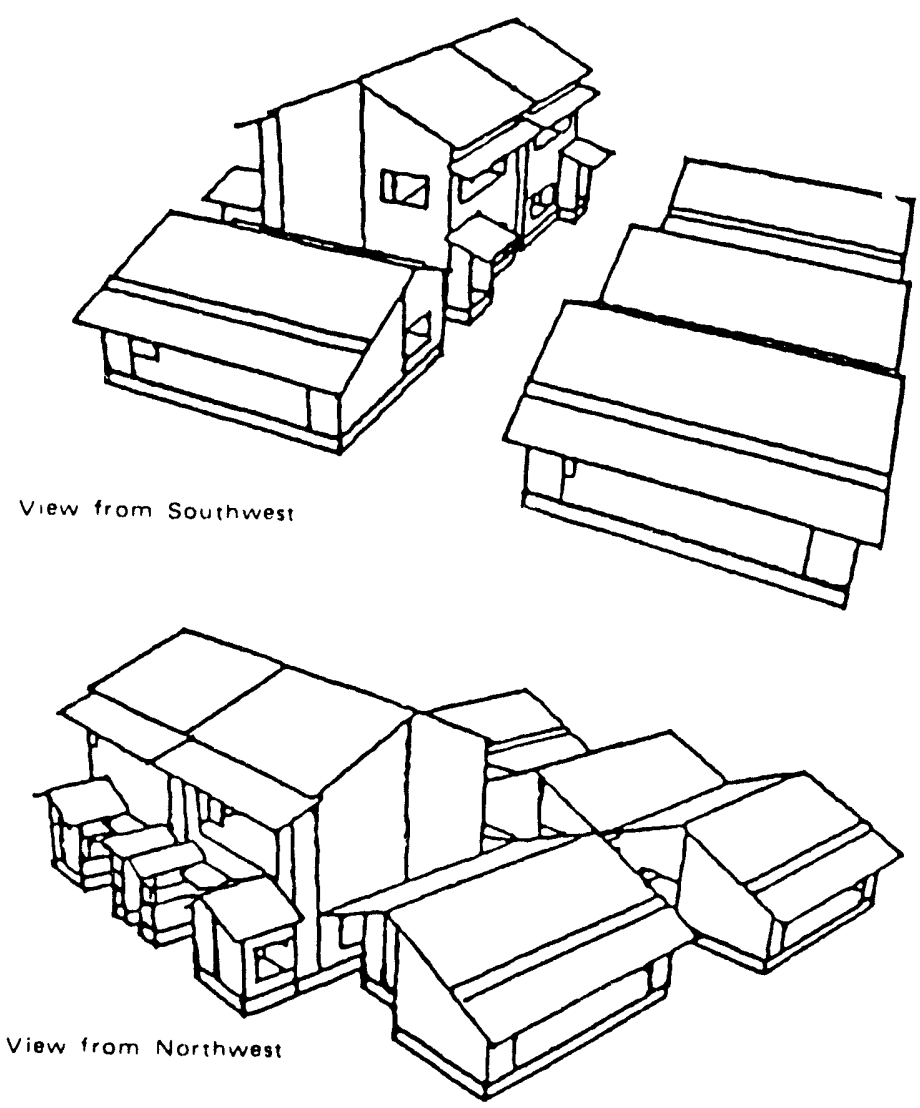

Combinatorial geometry of the six-house cluster model

Dimensions of Model Japanese Houses (cm)

\begin{tabular}{lccccc}
\hline House Type & Roof Peak & Length & Width & $\begin{array}{c}\text { Second Story } \\
\text { Floor Height }\end{array}$ & $\begin{array}{c}\text { Partition } \\
\text { Heighi }\end{array}$ \\
\hline Single story hous A & 475 & 872 & 700 & - & 270 \\
Two story house B & 915 & $858^{8}$ & 675 & 400 & 315 \\
Tenement (one unit) & 860 & $700^{8}$ & 500 & 360 & 300 \\
\hline
\end{tabular}

Main portion of hous

Fig. 10. Geometry for Test Problem 4: BREN Six-House Cluster. 

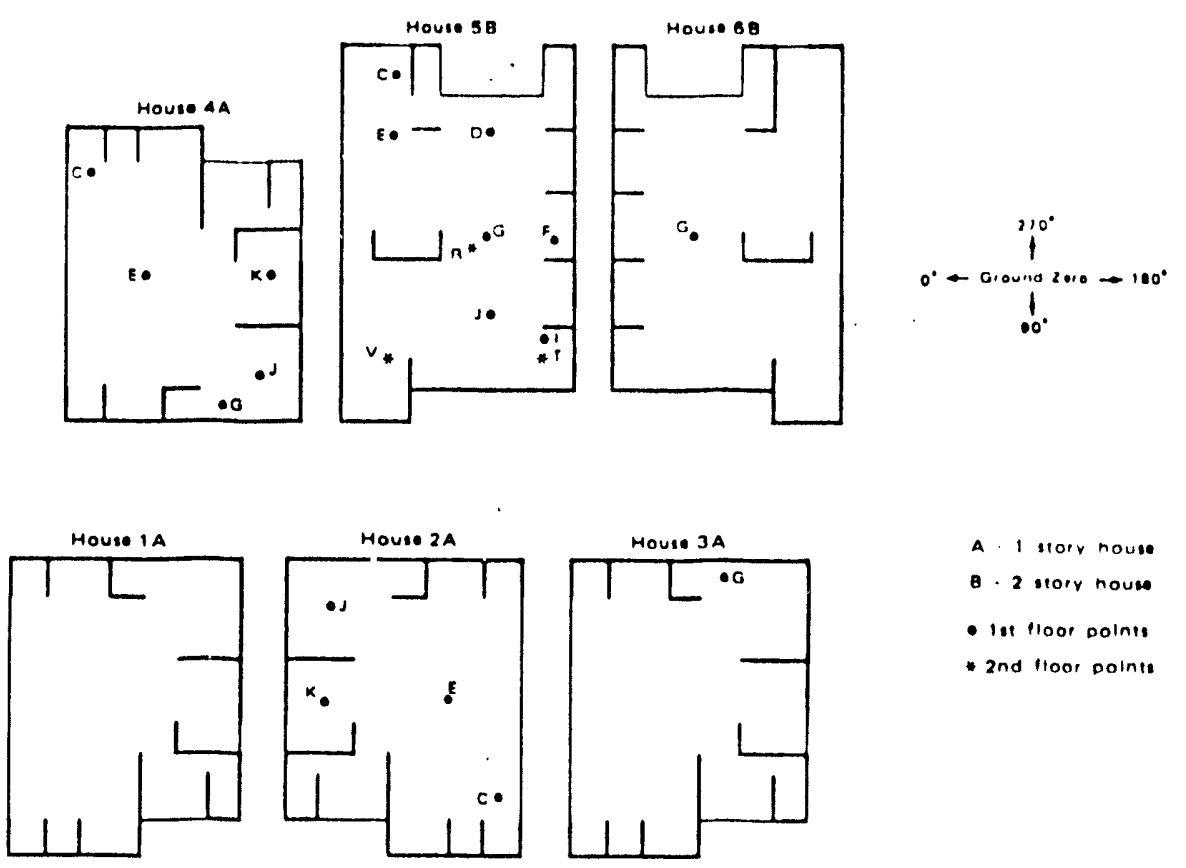

Plan of the six-house cluster showing location of detectors

Fig. 11. Plan View of the Geometry for Test Problem 4: BREN Six-House Cluster. 
Table 5. Comparison of DRC2 Calculated Soft Tissue Kerma Total Protection Factors for Test Problem 4: BREN Six-House Cluster

\begin{tabular}{|c|c|c|c|c|}
\hline \multirow[b]{2}{*}{ Range (m) } & \multirow[b]{2}{*}{$\begin{array}{l}\text { Orientation } \\
\text { (degrees) }\end{array}$} & \multicolumn{2}{|c|}{$\begin{array}{l}\text { Soft Tissue Kerma } \\
\text { Total Protection Factor }\end{array}$} & \multirow[b]{2}{*}{$\%$ Difference* } \\
\hline & & $\begin{array}{l}\text { With No X-Y } \\
\text { Dependence }\end{array}$ & $\begin{array}{l}\text { With X-Y } \\
\text { Dependence }\end{array}$ & \\
\hline 700 & 0 & 1.509 & 1.481 & -1.86 \\
\hline 700 & 90 & 1.682 & 1.632 & -2.97 \\
\hline 700 & 180 & 3.378 & 3.349 & -0.86 \\
\hline 700 & 270 & 1.825 & 1.780 & -2.47 \\
\hline 1000 & 0 & 1.341 & 1.352 & 0.82 \\
\hline 1000 & 90 & 1.836 & 1.817 & -1.03 \\
\hline 1000 & 180 & 4.514 & 4.472 & -0.93 \\
\hline 1000 & 270 & 2.244 & 2.191 & -2.36 \\
\hline 1500 & 0 & 1.098 & 1.095 & -0.27 \\
\hline 1500 & 90 & 1.846 & 1.826 & -1.08 \\
\hline 1500 & 180 & 5.8. & 5.682 & -2.44 \\
\hline 1500 & 270 & 3.009 & 2.922 & -2.89 \\
\hline 2000 & 0 & 0.945 & 0.939 & -0.63 \\
\hline 2000 & 90 & 1.824 & 1.804 & -1.10 \\
\hline 2000 & 180 & 6.596 & 6.393 & -3.08 \\
\hline 2000 & 270 & 3.654 & 3.597 & -1.56 \\
\hline
\end{tabular}


Table 6. Comparison of DRC and DRC2 Calculated Soft Tissue Kerma Protection Factors for Test Problem 4: BREN Six-House Cluster

\begin{tabular}{|c|c|c|c|c|}
\hline \multirow[b]{2}{*}{ Range (m) } & \multirow{2}{*}{$\begin{array}{l}\text { Orientation } \\
\text { (degrees) }\end{array}$} & \multicolumn{2}{|c|}{$\begin{array}{c}\text { Soft Tissue Kerma } \\
\text { Total Protection Factor }\end{array}$} & \multirow[b]{2}{*}{$\%$ Difference $^{*}$} \\
\hline & & $\mathrm{DRC}$ & $\mathrm{DRC} 2$ & \\
\hline 700 & 0 & 1.506 & 1.481 & -1.66 \\
\hline 700 & 90 & 1.680 & 1.632 & -2.86 \\
\hline 700 & 180 & 3.372 & 3.349 & -0.68 \\
\hline 700 & 270 & 1.822 & 1.780 & -2.31 \\
\hline 1000 & 0 & 1.339 & 1.352 & 0.97 \\
\hline 1000 & 90 & 1.832 & 1.817 & -0.82 \\
\hline 1000 & 180 & 4.506 & 4.472 & -0.75 \\
\hline 1000 & 270 & 2.241 & 2.191 & -2.23 \\
\hline 1500 & 0 & 1.096 & 1.095 & -0.09 \\
\hline 1500 & 90 & 1.843 & 1.826 & -0.92 \\
\hline 1500 & 180 & 5.813 & 5.682 & -2.25 \\
\hline 1500 & 270 & 3.003 & 2.922 & -2.70 \\
\hline 2000 & 0 & 0.943 & 0.939 & -0.42 \\
\hline 2000 & 90 & 1.821 & 1.804 & -0.93 \\
\hline 2000 & 180 & 6.584 & 6.393 & -2.90 \\
\hline 2000 & 270 & 3.647 & 3.597 & -1.37 \\
\hline
\end{tabular}


Table 7. Comparison of DRC and DRC2 Calculated Soft Tissue Kerma for Test Problem 4:

BREN Six-House Cluster

\begin{tabular}{ccccc}
\hline & & \multicolumn{2}{c}{ Soft Tissue Kerma* } & \\
\cline { 3 - 4 } Range $(\mathrm{m})$ & (degrees) & DRC & DRC2 (X-Y ciep) & \% Difference** \\
\hline 700 & 0 & $9.23+2^{* * *}$ & $9.73+2$ & 5.42 \\
700 & 90 & $8.28+2$ & $8.72+2$ & 5.31 \\
700 & 180 & $4.12+2$ & $4.01+2$ & -2.67 \\
700 & 270 & $7.63+2$ & $7.65+2$ & 0.26 \\
1000 & 0 & $2.78+2$ & $2.86+2$ & 2.88 \\
1000 & 90 & $2.03+2$ & $2.10+2$ & 3.45 \\
1000 & 180 & $8.26+1$ & $8.07+1$ & -2.30 \\
1000 & 270 & $1.66+2$ & $1.67+2$ & 0.60 \\
1500 & 0 & $4.44+1$ & $4.59+1$ & 3.38 \\
1500 & 90 & $2.64+1$ & $2.72+1$ & 3.03 \\
1500 & 180 & $8.36+0$ & $8.32+0$ & -0.48 \\
1500 & 270 & $1.62+1$ & $1.64+1$ & 1.23 \\
2000 & 0 & $8.29+0$ & $8.58+0$ & 3.50 \\
2000 & 90 & $4.29+0$ & $4.42+0$ & 3.03 \\
2000 & 180 & $1.19+0$ & $1.19+0$ & - \\
2000 & 270 & $2.14+0$ & $2.14+0$ & - \\
\hline
\end{tabular}

*The DRC2-calculated free-field kerma values are 1393, 372.9, 48.7, and 7.831 at $700 \mathrm{~m}, 1000 \mathrm{~m}, 1500 \mathrm{~m}$, and $2000 \mathrm{~m}$, respectively. They differ slightly from the DRC values because of logarithmic versus linear interpolation in the $Z$ direction. The $x-y$ dependent values vary from about $2 \%$ below to $3.5 \%$ above the reference values.

**( $\left(\frac{\text { DRC2 }}{\text { DRC }}-1\right) \times 100$.

$* * *$ Read as $9.23 \times 10^{2}$. 
results for all four orientations were obtained from a single calculation. The DRC2 calculation was performed for all ranges and orientations in a single pass through the code. In addition, the core allocation was large enough that fluence data for all groups could be stored in core during coupling $(430,000$ words were allocated versus slightly more than 423,000 required). The DRC core allocation was fixed at 150,000 words. Both the DRC and DRC2 calculations were performed for two source conditions, and $\mathrm{DRC} 2$ performed the calculations with and without $\mathrm{x}-\mathrm{y}$ dependence of the forward fluence during coupling. For these calculational conditions, the DRC to $\mathrm{DRC} 2$ charge ratios for the case of no $\mathrm{x}-\mathrm{y}$ dependence in the DRC2 coupling were $1.90,2.34,0.65$, and 1.79 for CPU, IO, memory, and total charges, respectively. The respective ratios for the case with $\mathrm{x}-\mathrm{y}$ dependence in DRC2 were $1.91,3.23,0.76$, and 1.88. IO and memory charges for a DRC2 calculation having no $x-y$ dependence in the coupling with one of the sources appeared to be anomalous. The IO charge was $75 \%$ higher than that for the $x-y$ dependent coupling case with the same source and $80 \%$ higher than that for both no $x-y$ and $x-y$ dependent coupling with the

other source. Smaller differences were noted for the memory charges. The memory charge was $37 \%$ high $r$ than that for the $x-y$ dependent coupling case with the same source and $25 \%$ higher than that for both no $x-y$ and $x-y$ dependent coupling with the other source.

From the above time comparisons, it would appear that DRC2 has a distinct advantage in all categories except memory, for which DRC has a slight advantage. The larger memory charge for DRC2 may be attributed to the greater amount of storage allocated (280,000 more words than DRC). Also, it can be noted from the above data that the IO and memory charges can fluctuate significantly between similar calculations (compare the no $x-y$ dependent versus the $x-y$ dependent cases). While the CPU charges are about the same for the two DRC2 cases, IO charges differ by about $38 \%$ and memory charges differ by about $17 \%$.

\subsection{TEST PROBLEM 5: LARGE RADIUS, AIR-FILLED, ANNULAR, CYLINDRICAL CONCRETE TUNNEL}

The fifth test case involves the calculation of neutron and gamma-ray fluences and doses within a large-radius, $9.8 \mathrm{~m}$ wide, air-filled, annular, cylindrical concrete tunnel. The concrete walls surrounding the tunnel are $20 \mathrm{~cm}$ thick, and the tunnel is centered at a radius of $3.45 \times 10^{4} \mathrm{~cm}$. A sketch of the problem geometry is shown in Fig. 12. The geometry for the calculation is such that DORT should be able to calculate the desired quantities. Therefore, the DRC2-calculated results can be compared against reasonably well-known quantities and the accuracy of the DRC2 coupling process can be established.

Again, the DABL69 group structure that was used in test problem 3 is used here. The source and cross-section library are the same. An $\mathrm{S}_{12}$ quadrature (96 directions) was used initially rather than the 240-direction quadrature. However, the 240-direction quadrature is used in the final analysis, mainly to aid in the transport 


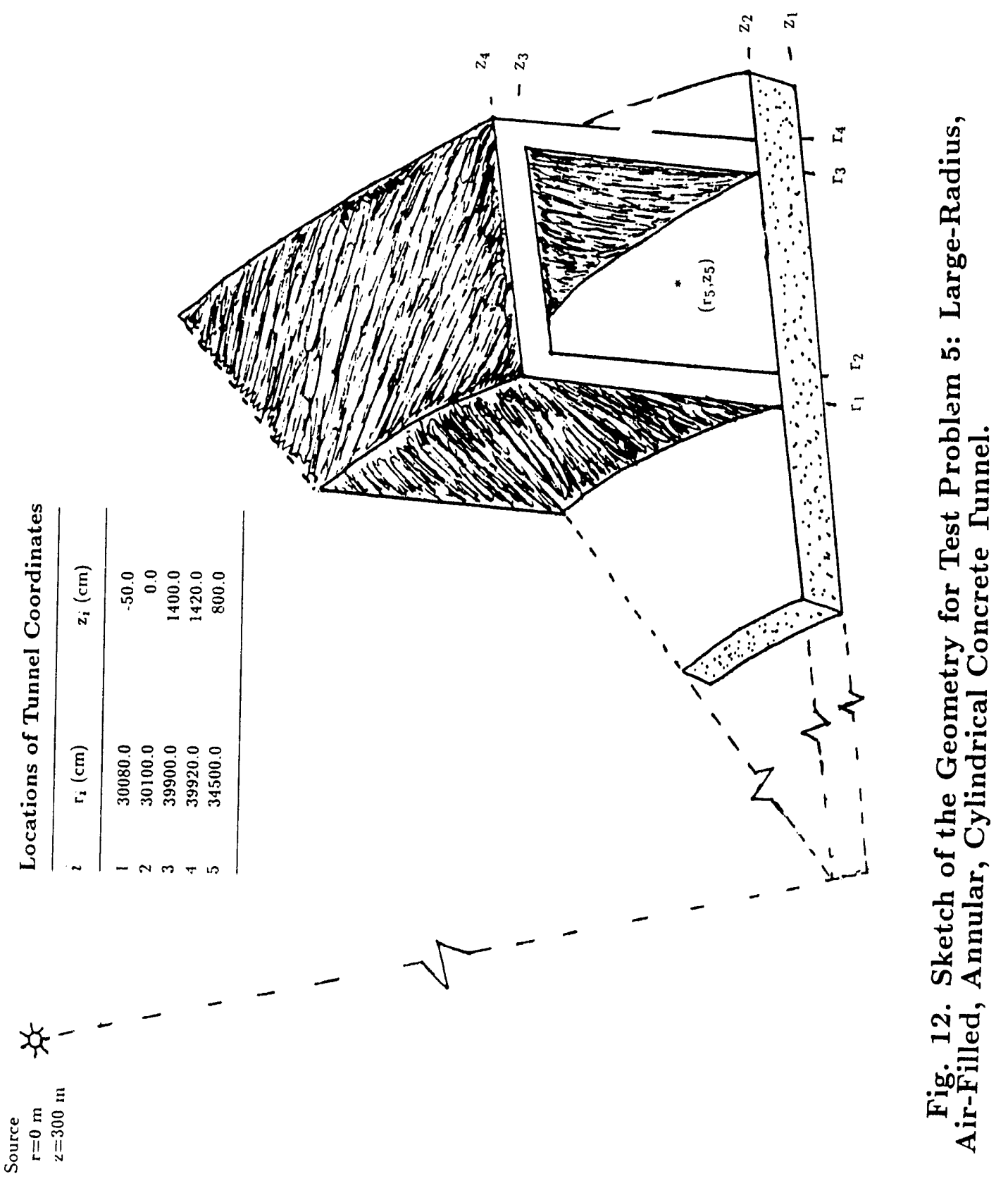


down range of secondary gamma rays produced near the source. In addition, two air-layer thicknesses are used in the MASHX calculations $(10.8 \mathrm{~m}$ and $50 \mathrm{~m})$. A mean-free-path in the air mixture ranges from 19 to $171 \mathrm{~m}$ for neutrons and 4.3 to $460 \mathrm{~m}$ for gamma rays. The optical thickness of the thicker air layer is several mean-free-paths for several neutron and gamma-ray groups. Hopefully, this layer is thick enough that the presence of the concrete tunnel would not perturb the free-field fluence at the system boundaries.

The DRC2 results obtained by folding adjoint leakages and forward fluences are compared to the DORT-calculated results in Table 8. Fractional standard deviations of the results are also given. With the 10.8-m-thick air layer, both the $x-y$ dependent and no $x-y$ depen.tent DRC2 results are reasonably close to the DORT results. The results without $x-y$ dependence are slightly lower. An analysis of the DRC2 results showed a sign:ficant contribution to the gamma-ray fluence and dose from the production of secondary gamma rays in the regions around the tunnel. As shown in the Table 8, all fractional standard deviations are less than 0.07 for the 10.8-m-thick air layer.

When one compares the results for the 50-m-thick air layer to those for the 10.8-m-thick air layer, one finds that overall agreement for the 50-m-thick air layer results improves for the $x-y$ dependent coupling case. In particular, excellent agreement is achieved for the neutron and gamma-ray fluences, but the agreement for the doses worsens slightly. Perhaps, the better agreement for the fluences may be attributed to the adjoint source being a fluence response function. The results obtained with no $x-y$ dependence in the coupling operation are lower than the DORT results by 14 to $25 \%$. Fractional standard deviations range from 0.034 to 0.085 . The good agreement between the DRC2 $\mathrm{x}$-y dependent results and the DORT results give added confidence in the correctness of the $\mathrm{DRC} 2$ coupling procedure.

As mentioned above, (Section 6.2) the air layer around the object should be thick enough that the fluence at the boundary of the air layer is not perturbed by the presence of the object. Since the 50-m-thick air layer led to better overall agreement with DORT than did the 10.8-m-thick air layer, perturbations to fluences at system boundaries with those air layer thicknesses were examined. Table 9 shows the maximum percent differences between the above-ground perturbed and unperturbed neutron and gamma-ray total fluences as a function of leakage surface. The six surfaces shown represent the leakage surfaces used in the MASHX calculations (i.e. a top and inner and outer radial surfaces bounding either a 10.8 - $m$-thick or a 50 $\mathrm{m}$-thick air layer surrounding the concrete tunnel). One can see that there is much more perturbation for the $10.8-\mathrm{m}$-thick air layer surfaces. The outer radial surface shows greater differences because the tunnel partially shields some points on that surface. 
Table 8. Comparison of DRC2 and DORT Calculated Fluences and Doses for Test Problem 5: Large-Radius, Air-Filled, Cylindrical Concrete Tunnel.

\begin{tabular}{lcc}
\hline \multicolumn{3}{c}{ DORT Calculation } \\
\hline Calculated Quantity & Perturbed & Unperturbed \\
\hline Neutron Fluence & $4.225+3^{\mathrm{a}}$ & $7.263+4$ \\
Gamma-Ray Fluence & $3.960+3$ & $3.881+4$ \\
Neutron Dose & $7.335-5$ & $1.361-3$ \\
Gamma-Ray Dose & $4.387-5$ & $4.243-4$ \\
\hline & DRC2 with 10.8-m-Thick Air Layer \\
\hline Calculated Quantity & With No X-Y & With X-Y \\
& Dependence & Dependence \\
\hline Neutron Fluence & $3.911+3[0.026](0.93)^{\mathrm{b}}$ & $4.035+3[0.027](0.96)$ \\
Gamma-P.a: Fluence & $4.010+3[0.066](1.04)$ & $4.209+3[0.067](1.06)$ \\
Neutron Dose & $6.761-5[0.035](0.92)$ & $6.975-5[0.034](0.95)$ \\
Gamma-Ray Dose & $4.295-5[0.066](0.98)$ & $4.408-5[0.066](1.00)$ \\
\hline & DRC2 with 50.0-m-Thick Air Laycr & \\
\hline Calculated Quantity & With No X-Y & With X-Y \\
& Dependence & Dependence \\
\hline Neutron Fluence & $3.650+3[0.042](0.86)$ & $4.228+3[0.044](1.00)$ \\
Gamma-Ray Fluence & $3.342+3[0.062](0.84)$ & $3.971+3[0.068](1.00)$ \\
Neutron Dose & $5.490-5[0.034](0.75)$ & $6.903-5[0.060](0.94)$ \\
\hline Gamma-Ray Dose & $3.730-5[0.078](0.85)$ & $4.506-5[0.085](1.03)$ \\
\hline
\end{tabular}

"Read as $4.225 \times 10^{3}$.

'Fractional standard deviations are in brackets and ratios of DRC2 to DORT quantities are in parentheses. 
Table 9.

Maximum Percent Differences Between the Above-Ground Perturbed and Unperturbed Neutron and Gamma-Ray Total Fluences as a Function of Leakage Surface for Test Problem 5: Large-Radius, Air-Filled, Cylindrical Concrete Tunnel.

\begin{tabular}{|c|c|c|}
\hline \multirow[b]{2}{*}{ Leakage Surface } & \multicolumn{2}{|c|}{ Maximum Percent Difference in Fluences* } \\
\hline & Neutron & Gamma-Ray \\
\hline \multicolumn{3}{|l|}{ Inner Radial } \\
\hline $\begin{array}{l}\text { 10.8-m Air Layer } \\
\text { 50.0-m Air Layer }\end{array}$ & $\begin{array}{c}10.5 \\
0.4\end{array}$ & $\begin{array}{l}3.3 \\
1.2 \\
\end{array}$ \\
\hline \multicolumn{3}{|l|}{ Outer Radial } \\
\hline $\begin{array}{l}\text { 10.8-m Air Layer } \\
\text { 50.0-m Air Layer }\end{array}$ & $\begin{array}{c}39.0 \\
9.3 \\
\end{array}$ & $\begin{array}{l}47.6 \\
14.2 \\
\end{array}$ \\
\hline \multicolumn{3}{|l|}{ Top } \\
\hline $\begin{array}{l}\text { 10.8-m Air Layer } \\
\text { 50.0-m Air Layer }\end{array}$ & $\begin{array}{c}8.8 \\
-1.4\end{array}$ & $\begin{array}{c}15.2 \\
6.7\end{array}$ \\
\hline$*\left(\frac{\text { Unperturbed Fluence }}{\text { Perturbed Fluence }}-1\right)$ & $\times 100$ & \\
\hline
\end{tabular}


For the top surface, the perturbation is significant for the 10.8-m-thick air layer but is much less for the 50 -m-thick air layer. There is probably less perturbation of the inward-directed fluences than that shown in Table 9.

It should be noted that the results for the MASHX calculations were quite sensitive to the GWLO values input. In addition, the value of NMOST had to be increased for some changes in GWLO due to "imaxn" being exceeded. Therefore, to eliminate the requirement for having to input these values and to guard against inappropriate selections of the parameters, the calculations were performed as if they were neutron only and a modified version of the MASHX code (called MASHY) sorted the various collision or pseudo-collision events. This required an additional input card following the last MASHX input card (the air and ground media identifiers). The input is free form; hence, the data should be preceded by ' $\$ \$$ ' in columns 2 and 3 . The two entries on the card are:

jptyp

a signal to indicate no effect if 0 or a coupled problem run as neutron-only if 1 , and

jprigp the number of neutron groups.

The code calculates the gamma-to-neutron transfer probabilities through the cross-section scattering matrix. MASHY uses the above parameters along with old and new group numbers to determine when a garnma-to-neutron transfer has occurred at real scattering events.

Finally, the change to a 240-direction quadrature and the inclusion of the thicker air layer in the MASHX calculation led to a very large data storage requirement in DRC2. Nearly six million words would be required to store all data in core (i.e. data for 69 groups, 200 nonzero weight directions, $10 \mathrm{i}$ mesh, and $42 \mathrm{j}$ mesh). The DRC2 calculation was performed with a core allocation of three million words. While a CPU charge of about two minutes was required for the four calculations (for two coupling surfaces with and without $x-y$ dependence during coupling), large memory and IO charges resulted in a total charge of about 30 minutes. For the DRC2 calculation of the perturbed fluence by integration of the perturbed DORT-VISTA angular fluences, the total charge was only about three seconds. 


\section{CONCLUSIONS}

The DRC2 code has been written and tested and appears to be performing the coupling operation correctly. Results have been compared with some from the DRC code and some simulated DRC results (obtained with $\mathrm{DRC} 2$ by coupling without $\mathrm{x}-\mathrm{y}$ dependence). Those results indicated that there were some significant effects (greater than 10\%) of including $x-y$ dependence in the coupling operation, but small effects were observed in small systems and even one reasonably large system. In addition, the good agreement for a test case solvable directly with DORT gave added assurance of the correctness of the coupling procedure.

Although the code allows for calculations with very large fluence data requirements to be solved "ex-core," one may incur a large IO cost penalty when data has to be stored ex-core. It is therefore recommended that, whenever possible, enough core be allocated so that all fluence data can be stored in core. 


\section{REFERENCES}

1. W. A. Rhoades and R. L. Childs, "The DORT Two-Dimensional Discrete Ordinates Transport Code," Nucl. Sci. \& Eng. 99, 1, 88-89 (May 1988).

2. M. B. Emmett, "The MORSE Monte Carlo Radiation Transport Code System," ORNL-4972 (1975), ORNL-4972/R1 (1983), ORNL-4972/R2 (1984), Union Carbide Corporation, Nuclear Division, Oak Ridge National Laboratory.

3. W. A. Rhoades, M. B. Emmett, G. W. Morrison, J. V. Pace, III, and L. M. Petrie, "Vehicle Code System (VCS) User's Manual," ORNL/TM-4648 (August 1974).

4. J. O. Johnson, editor, "A User's Manual for MASH 1.0 - A Monte Carlo Adjoint Shielding Code," ORNL/TM-11778 (in publication).

5. W. A. Rhoades and M. B. Emmett, "DOS: The Discrete Ordinates System," ORNL/TM-8362, September 1982.

6. D. E. Bartine, J. R. Knight, J. V. Pace, III, and R. Roussin, "Production and Testing of the DNA Few-Group Coupled Neutron-Gamma Cross-Section Library," ORNL/TM-4840, (1977).

7. D. T. Ingersoll, R. W. Roussin, C. Y. Fu, and J. E. White, "DABL69: A Broad-Group Neutron/Photon Cross-Section Library for Defense Nuclear Applications," ORNL/TM-10568 (1989).

8. W. C. Roesch, ed., "US-Japan Joint Reassessment of Atomic Bomb Radiation Dosimetry in Hiroshima and Nagasaki," Vol. 1, Radiation Effects Research Foundation, Hiroshima, Japan, 1987. 


\section{APPENDIX A \\ Partial Output Listing for Test Problem 1: \\ Free-Field Fluence Calculation}




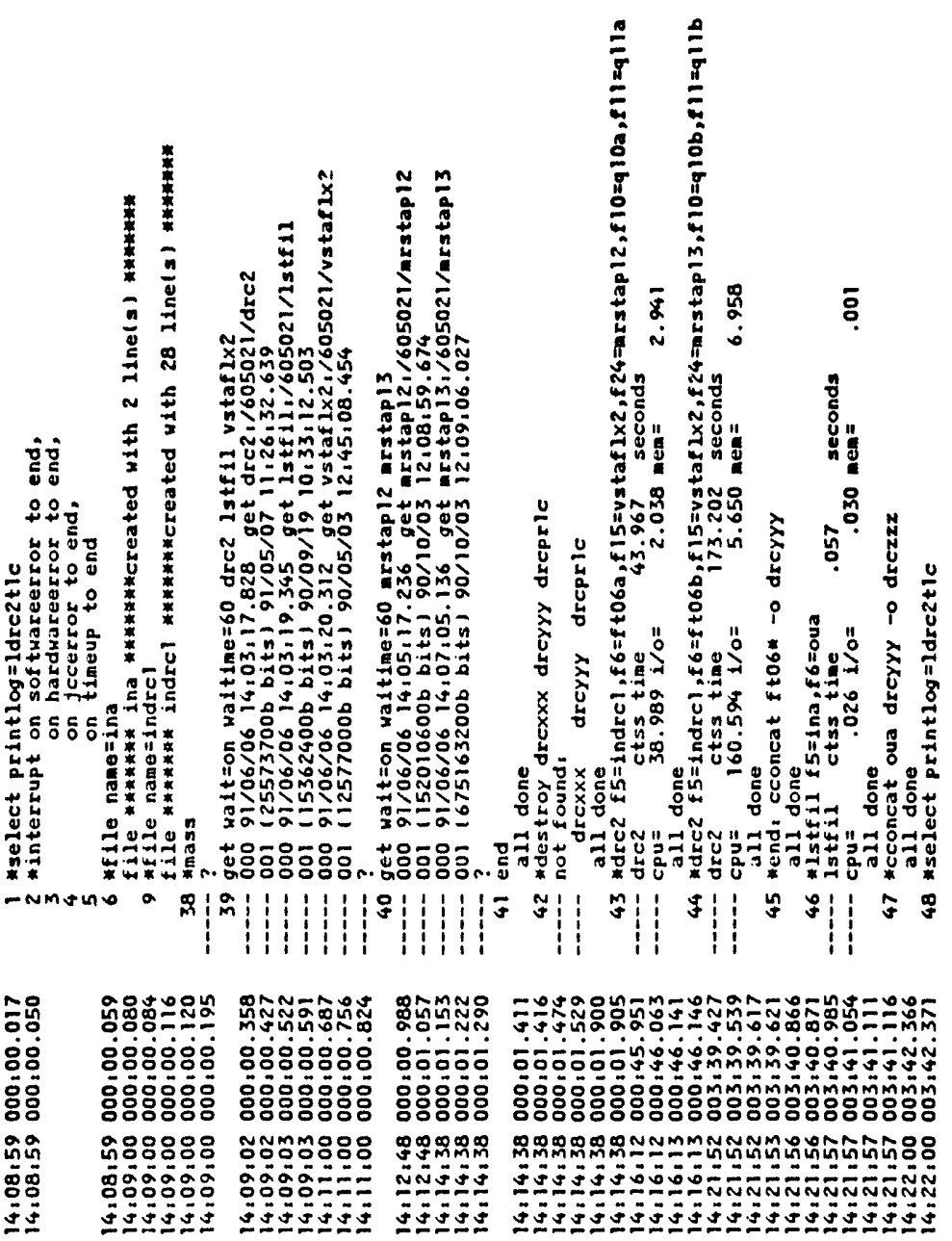



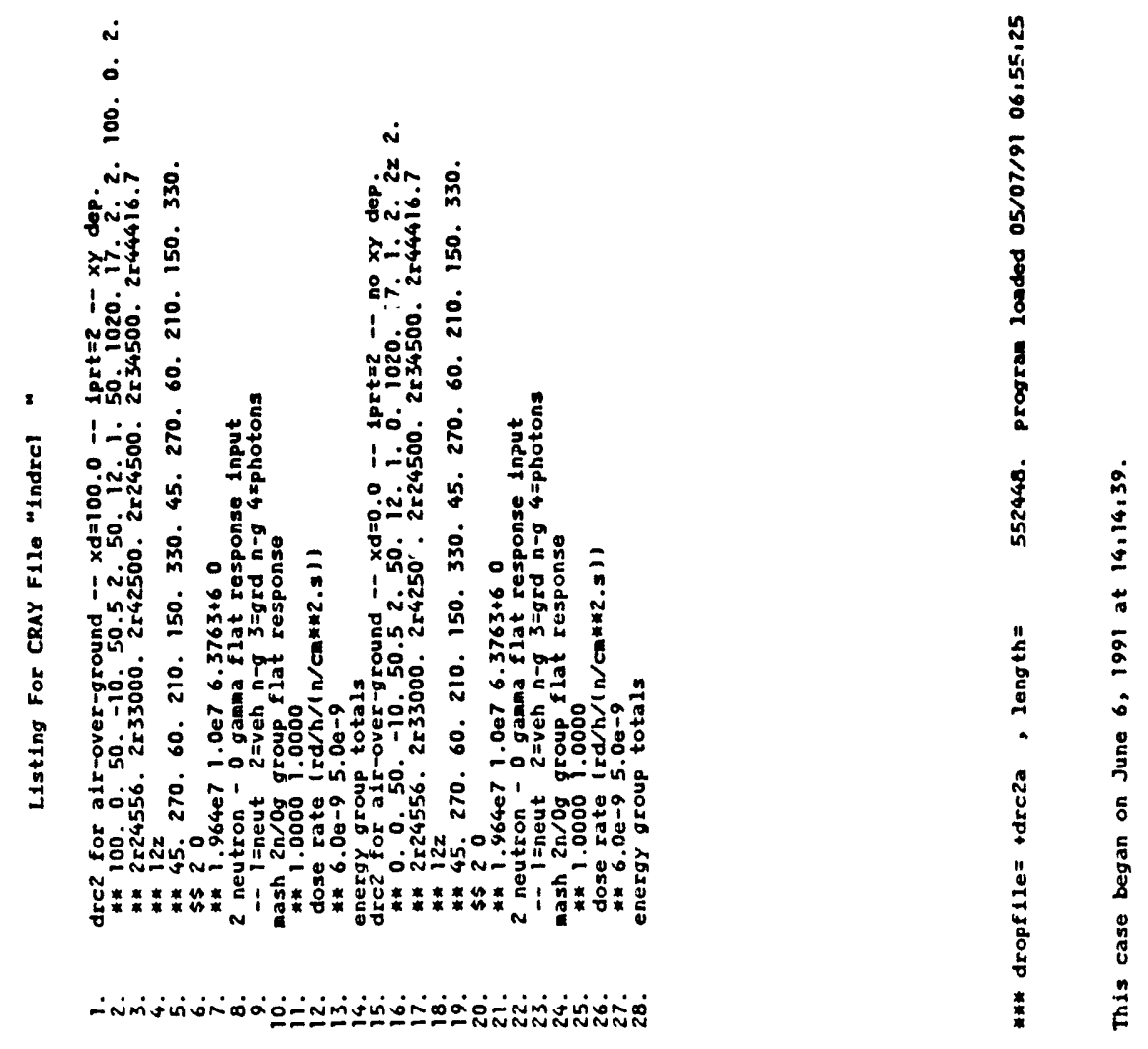


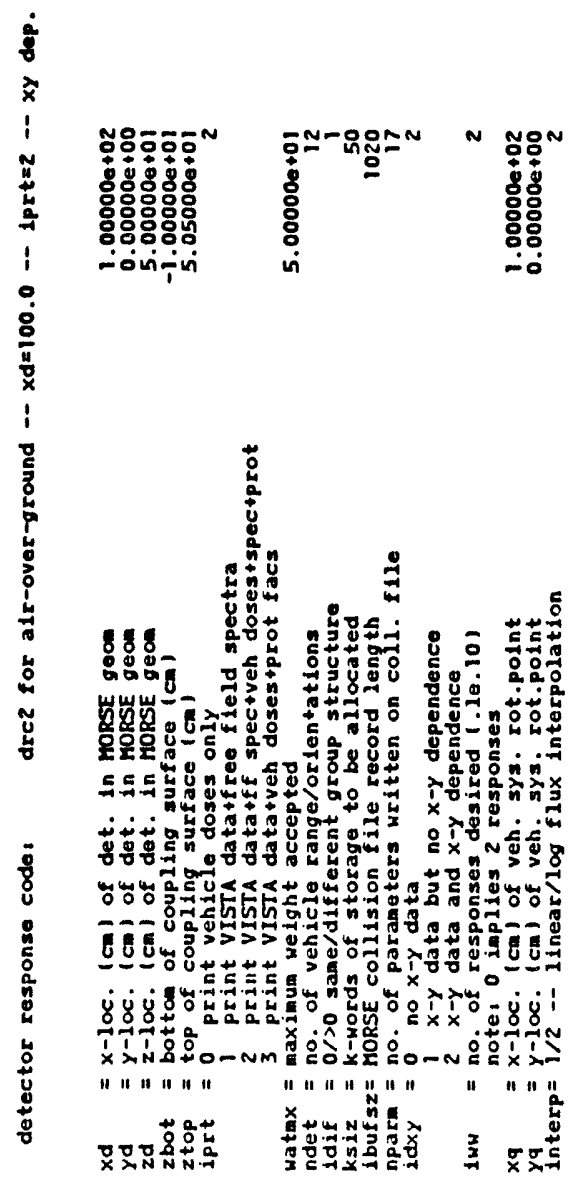




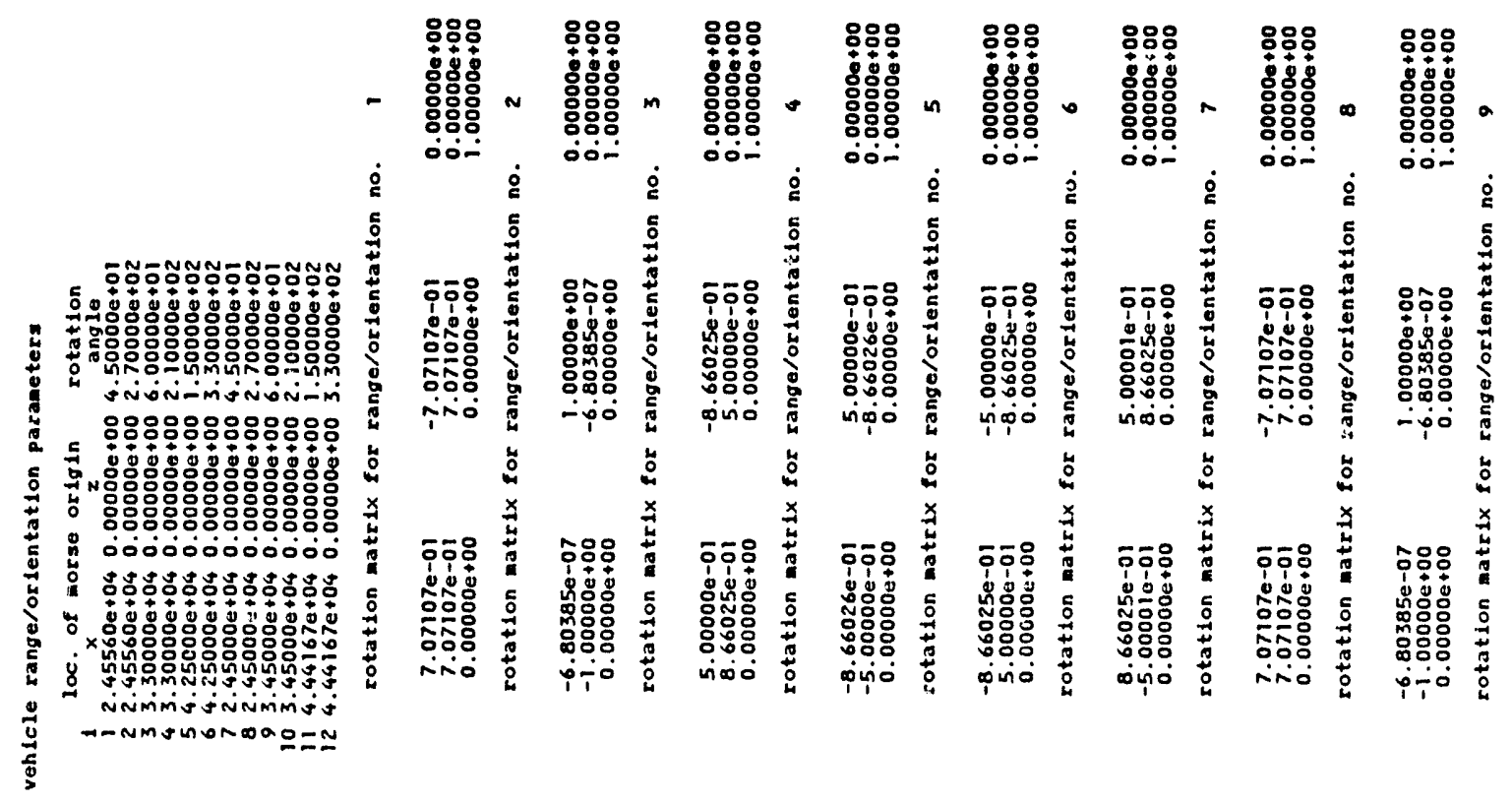



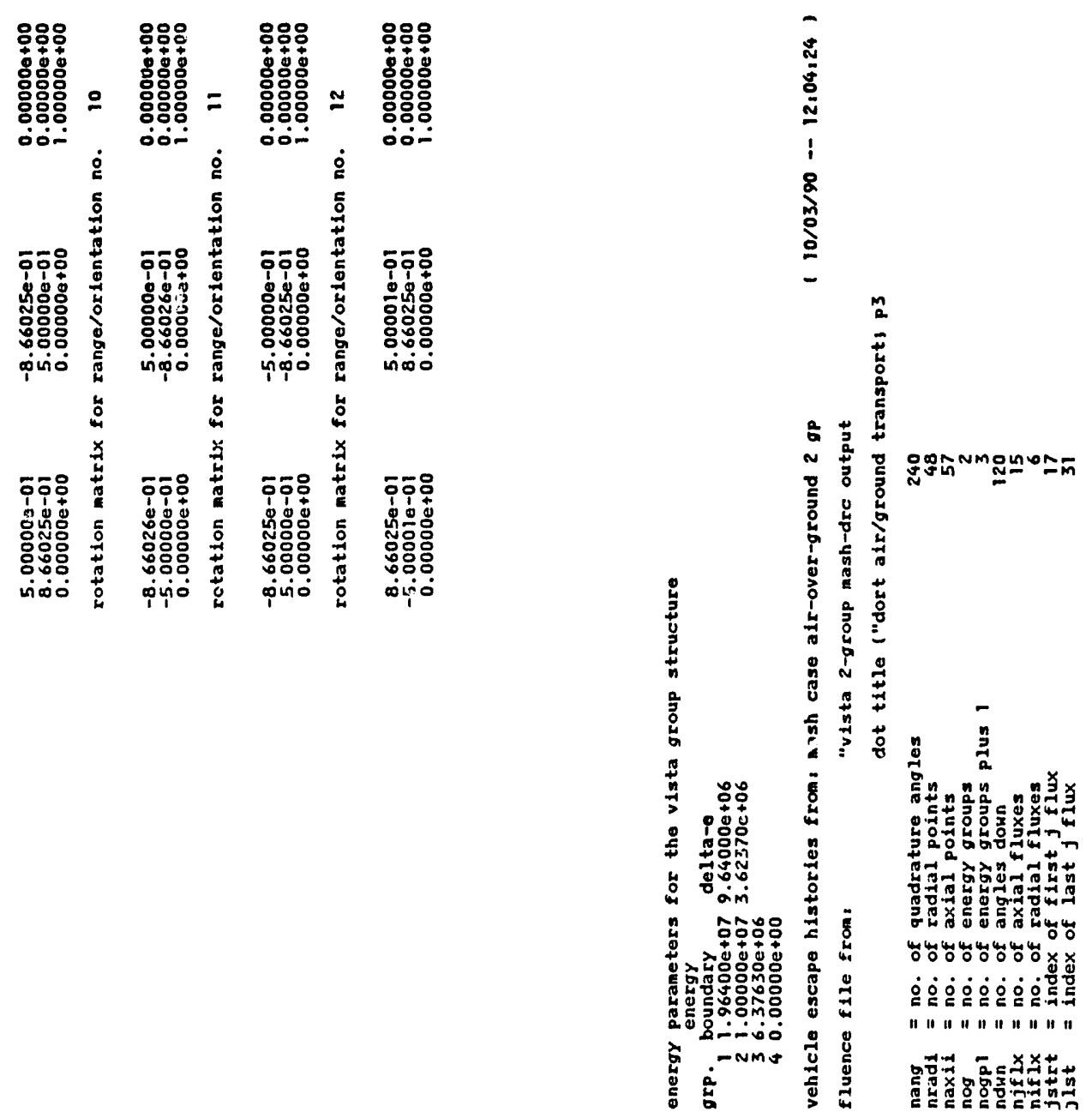


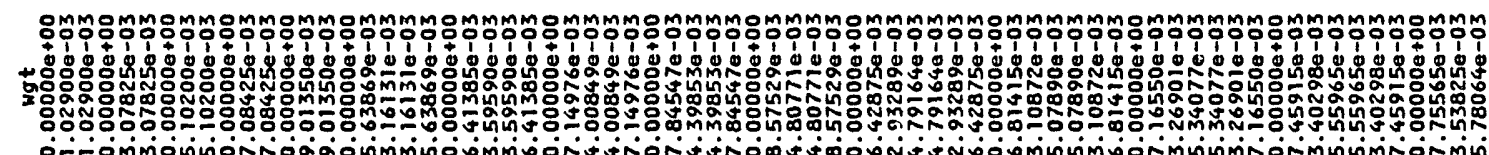

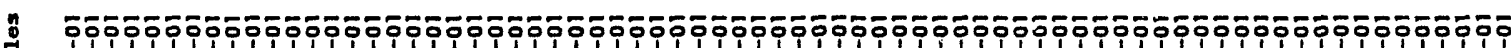

\%

to

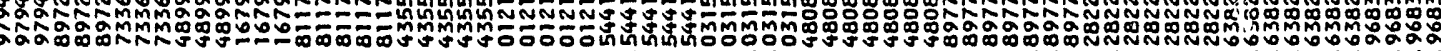
ada

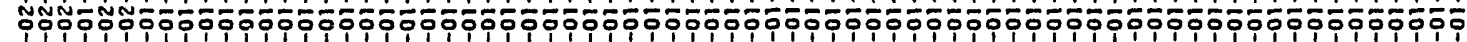

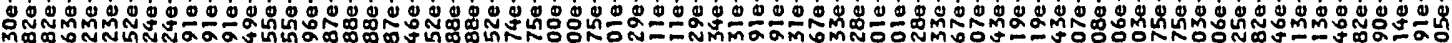
ZNM๊

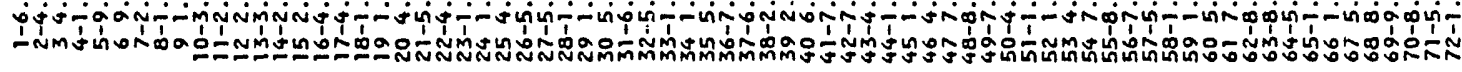




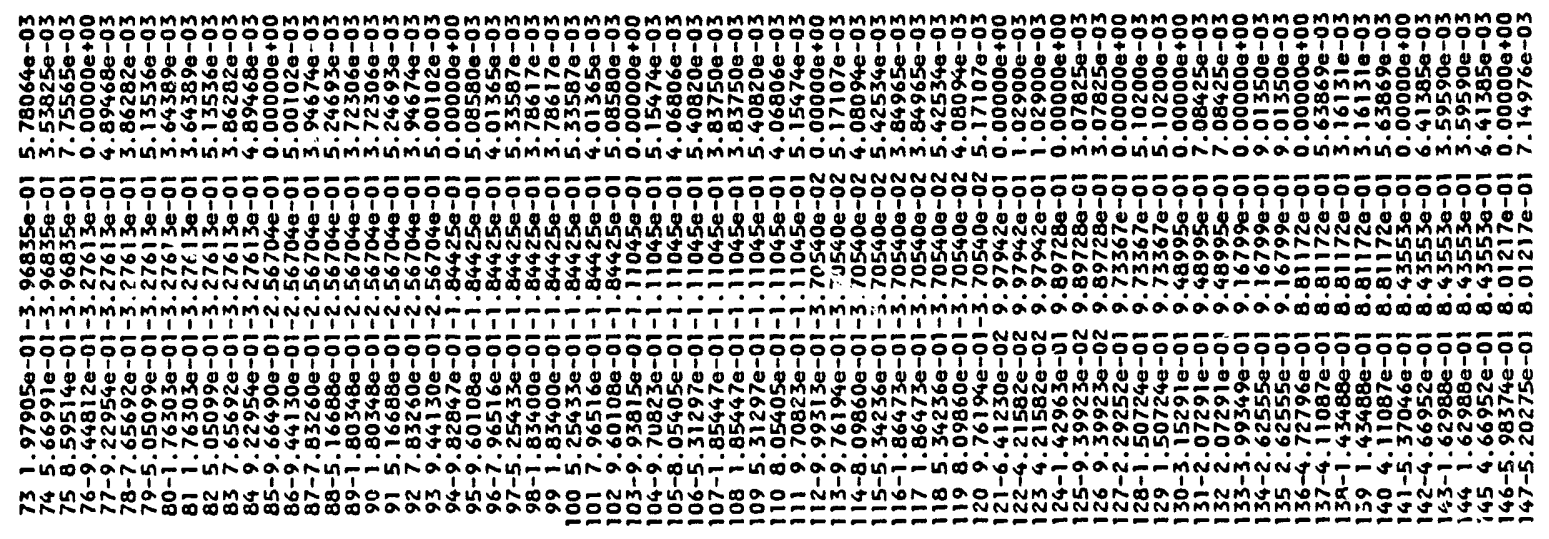




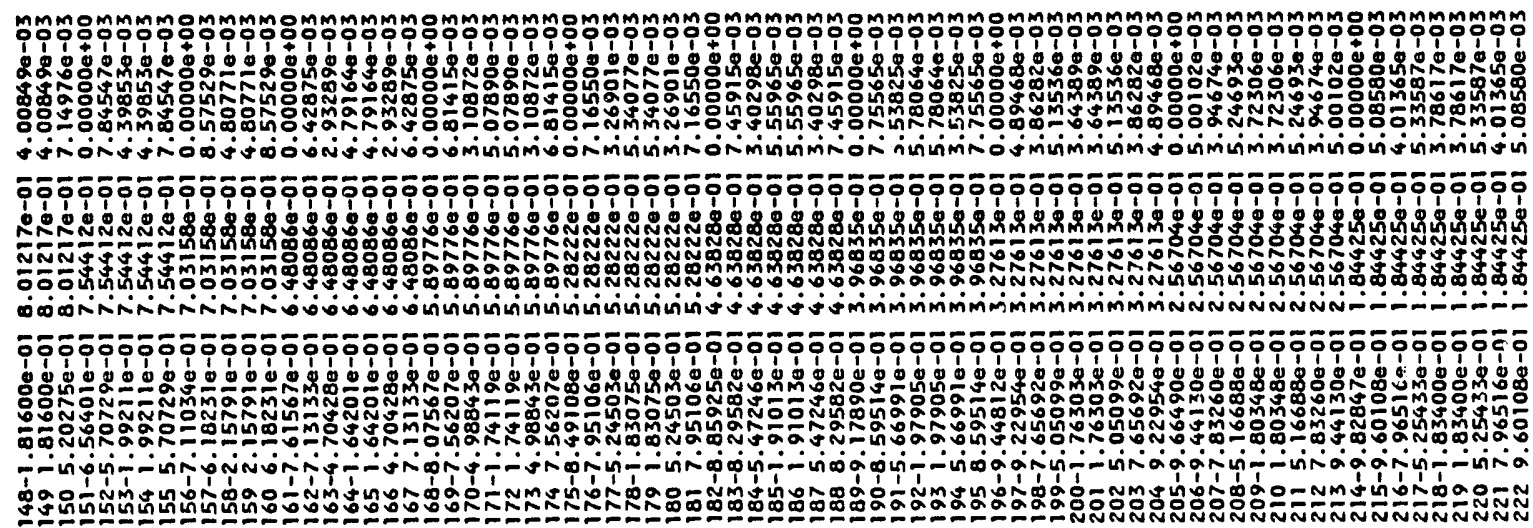




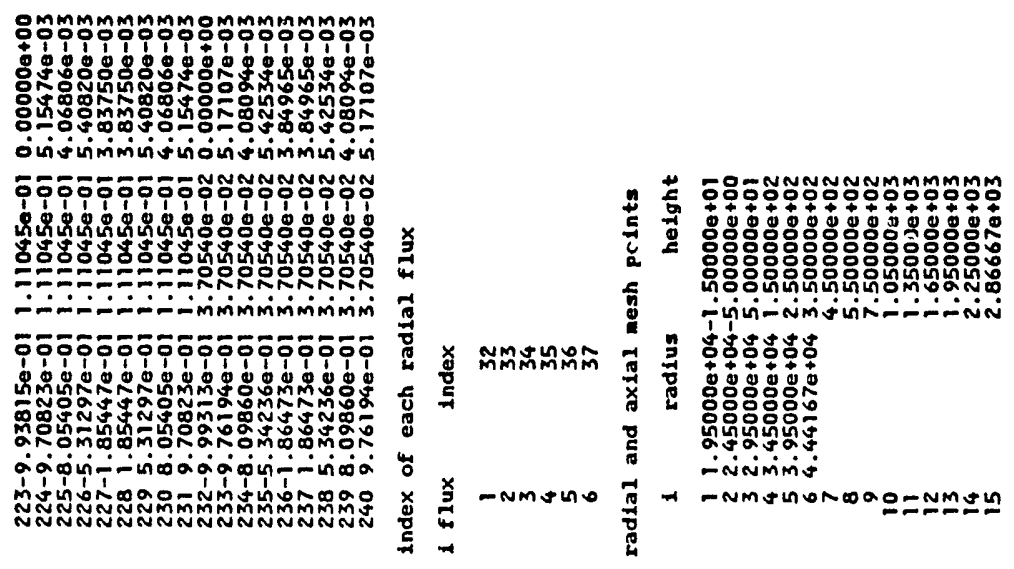




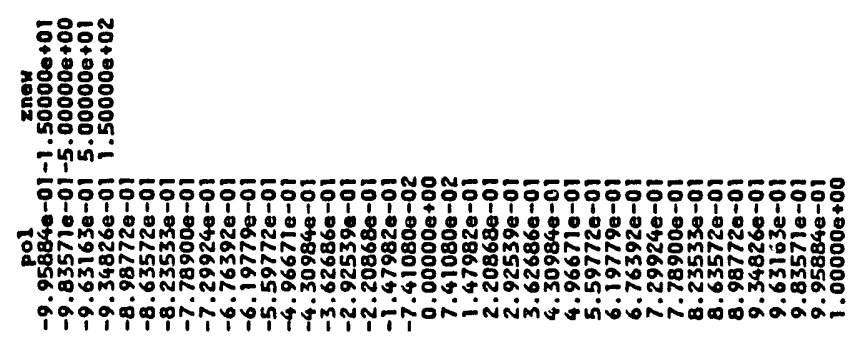

๕ัดง

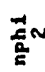

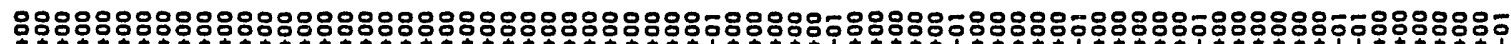

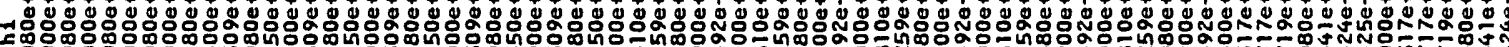

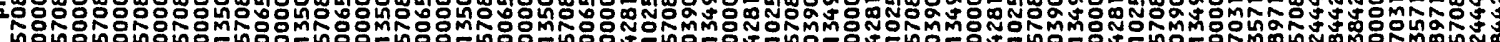

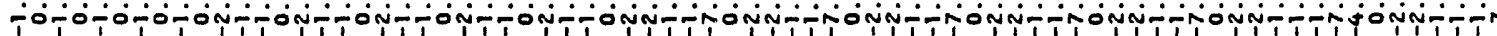

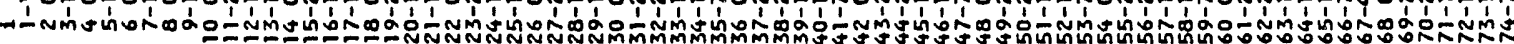




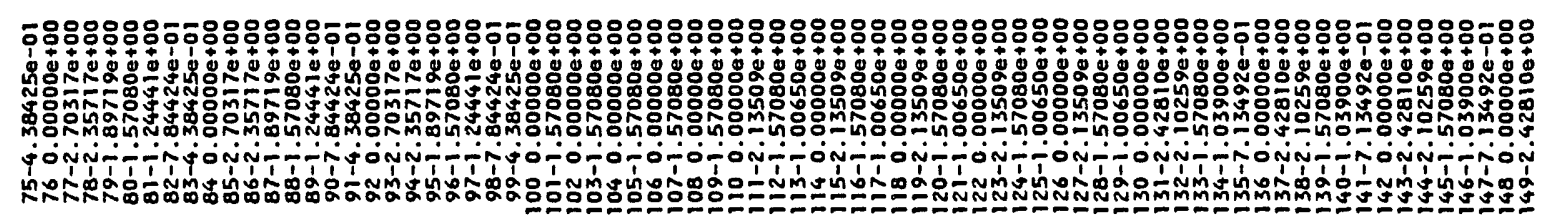




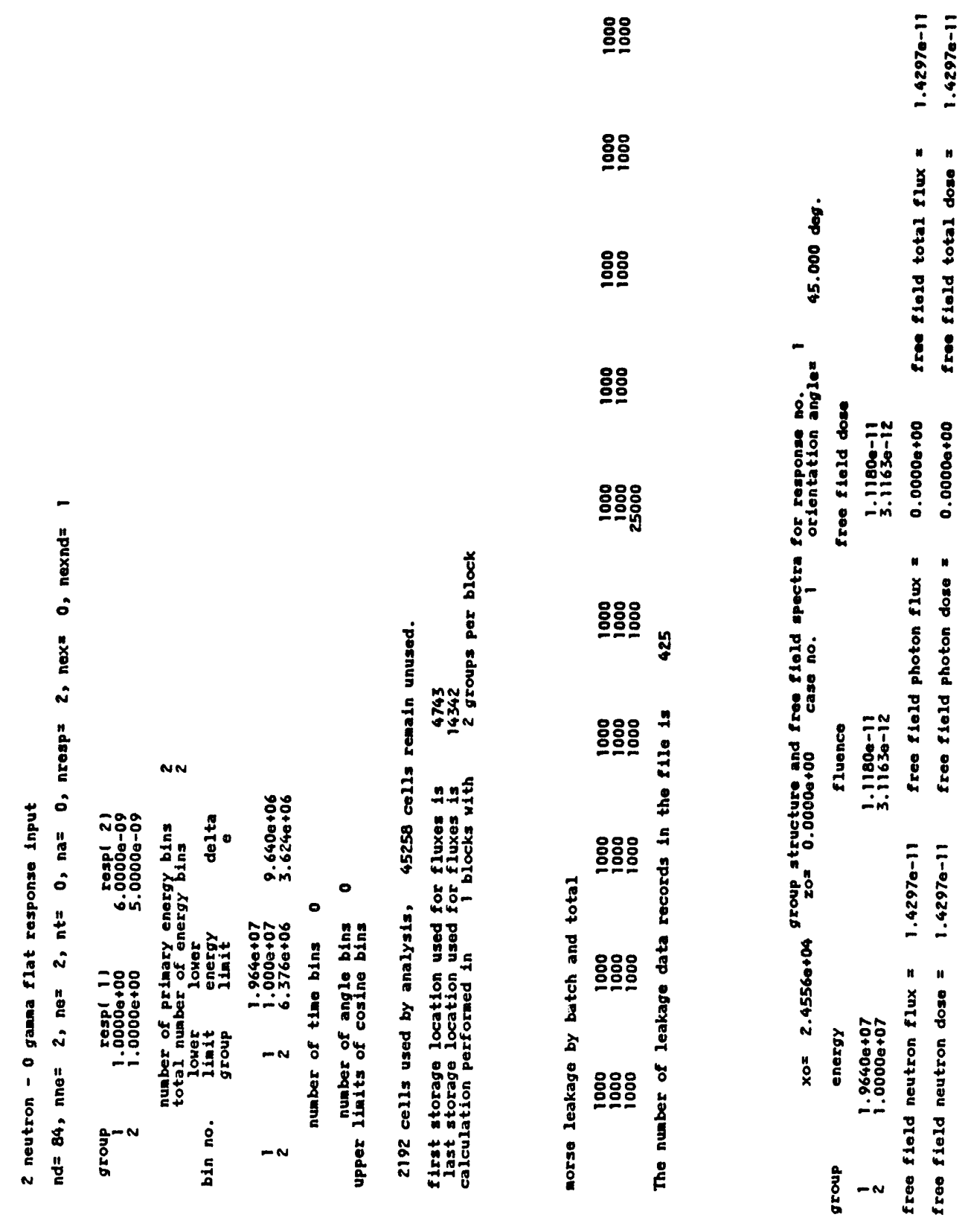



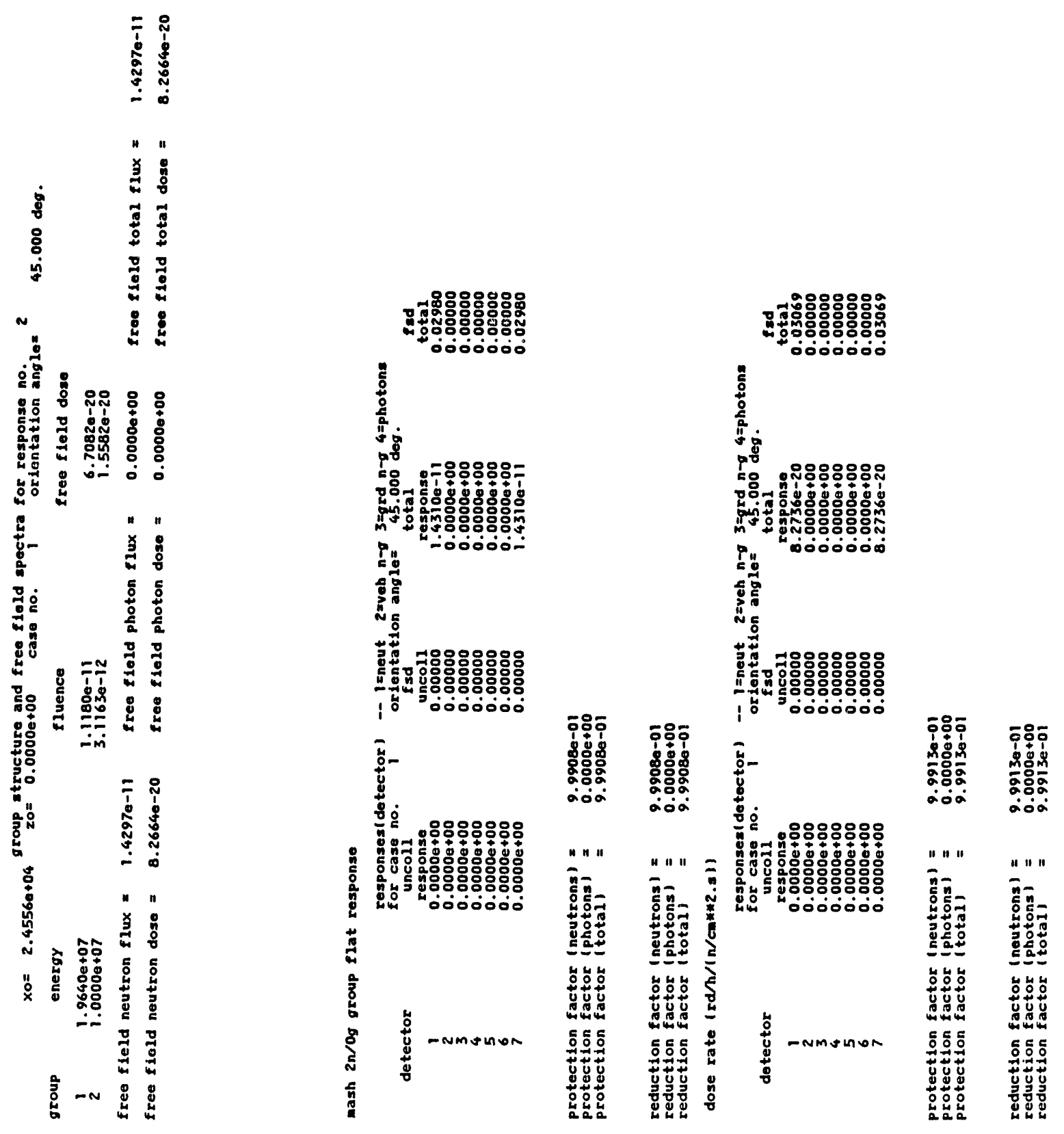


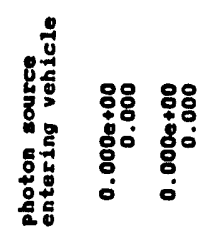

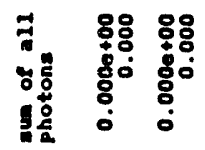
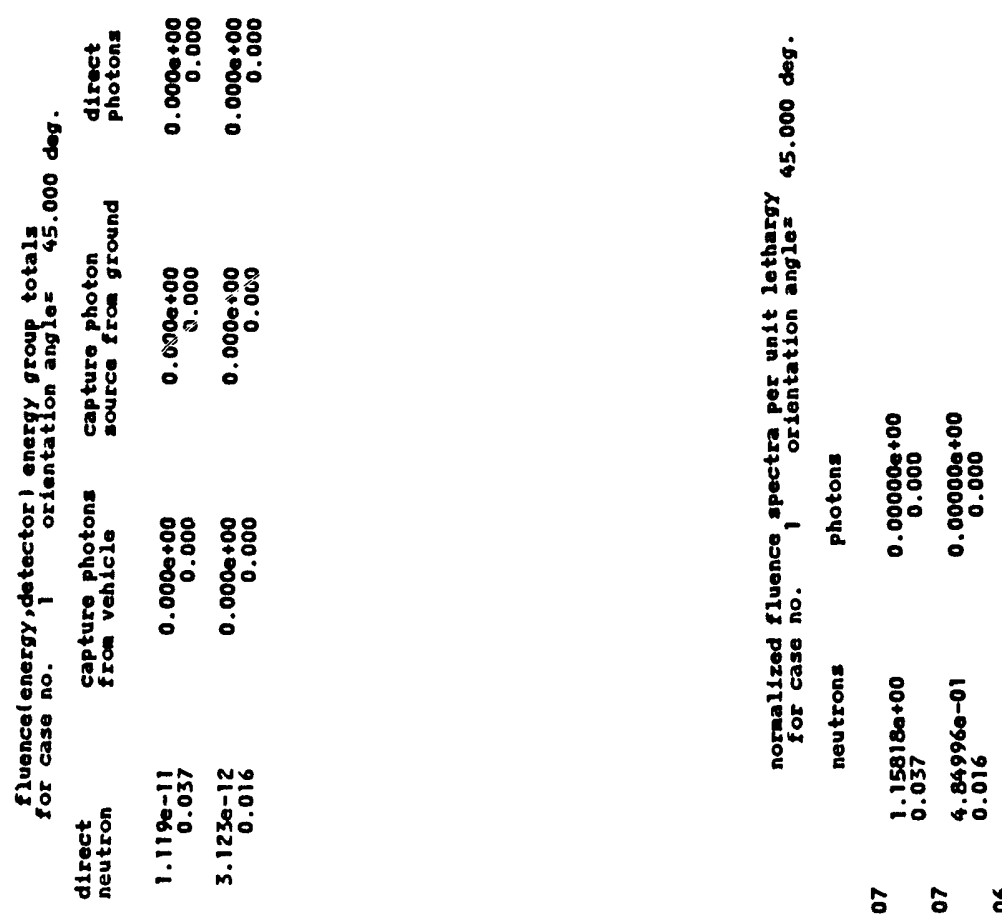

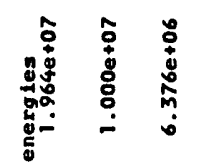

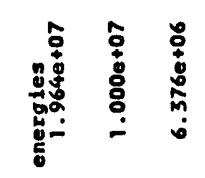



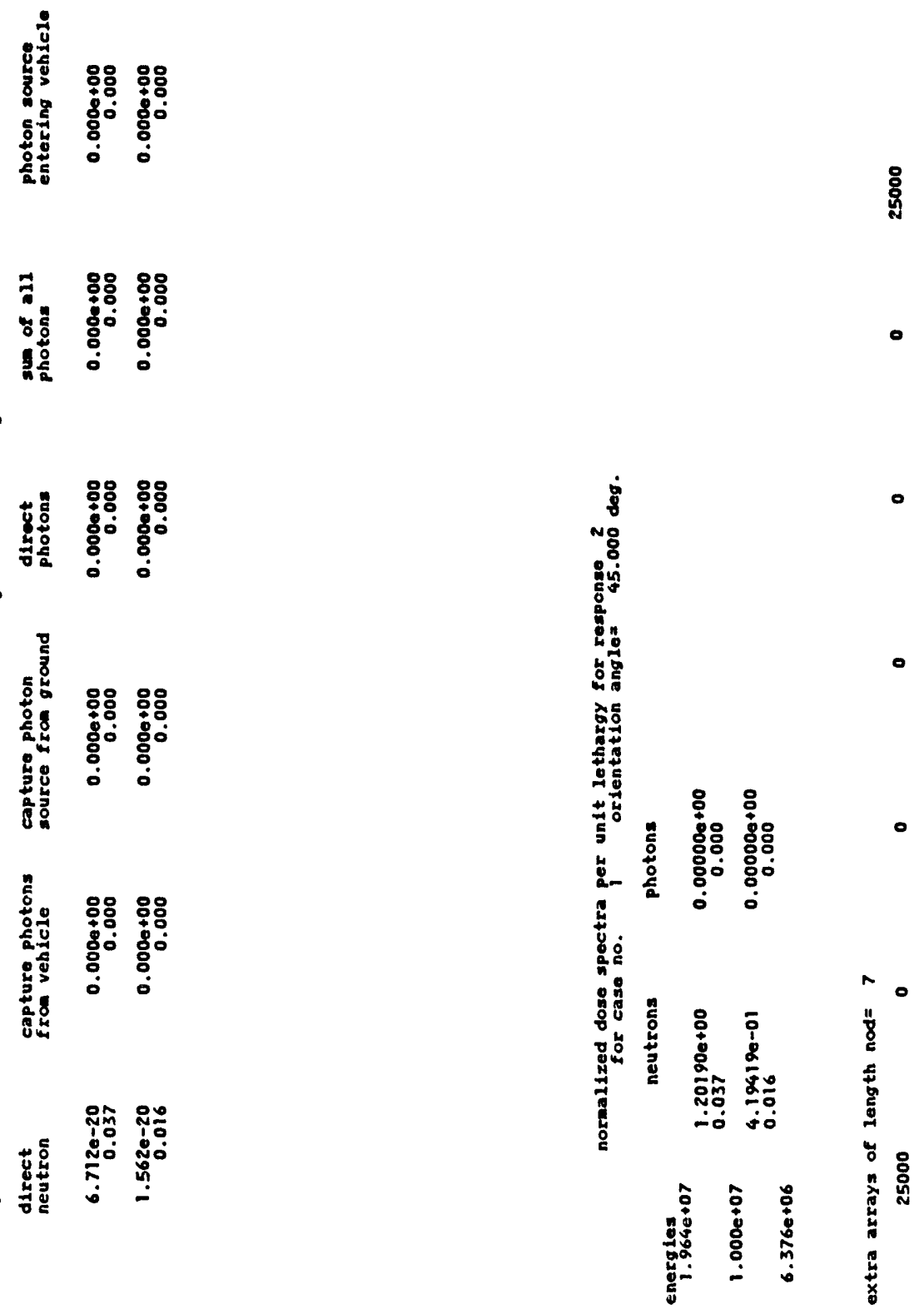

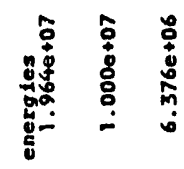



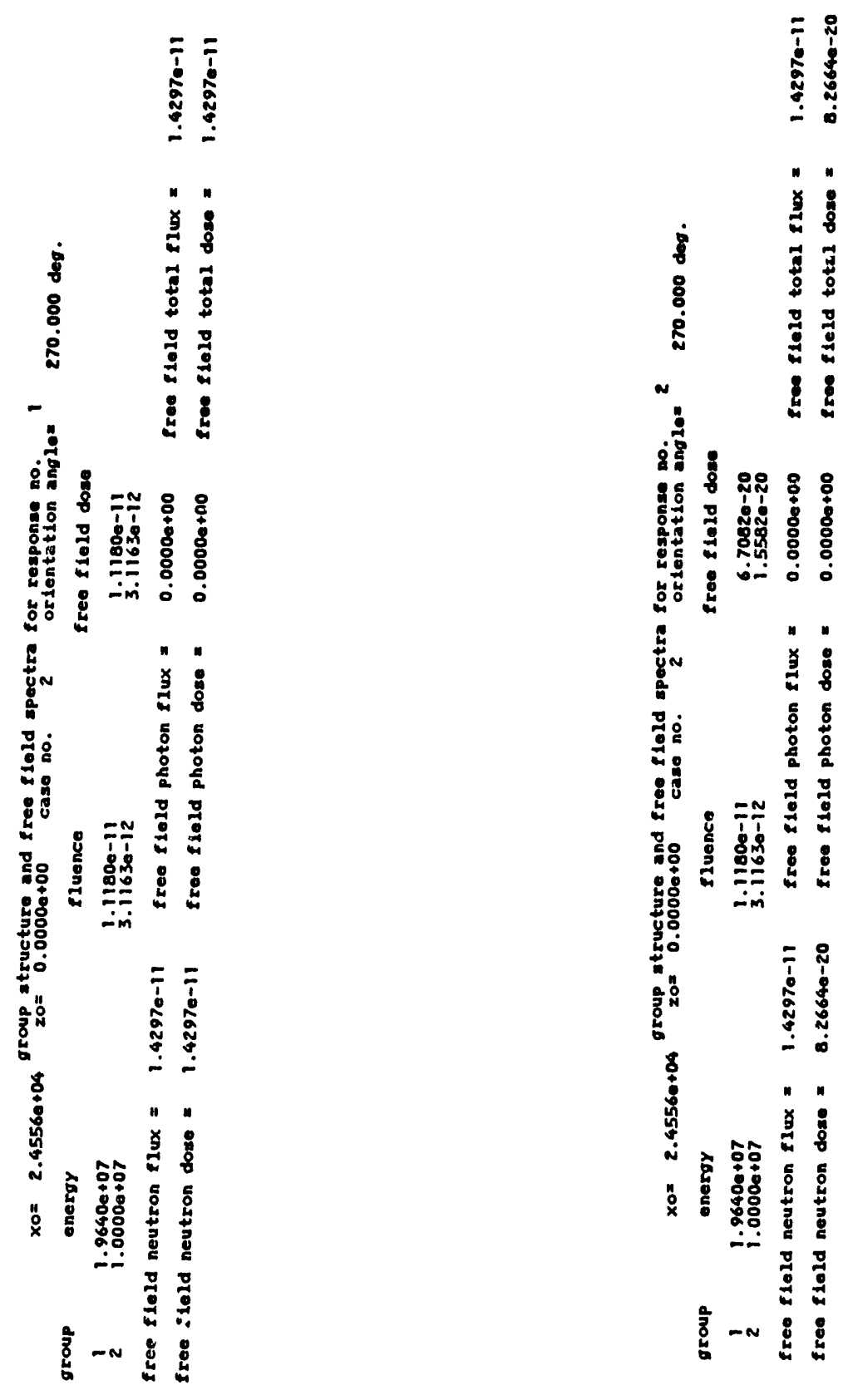


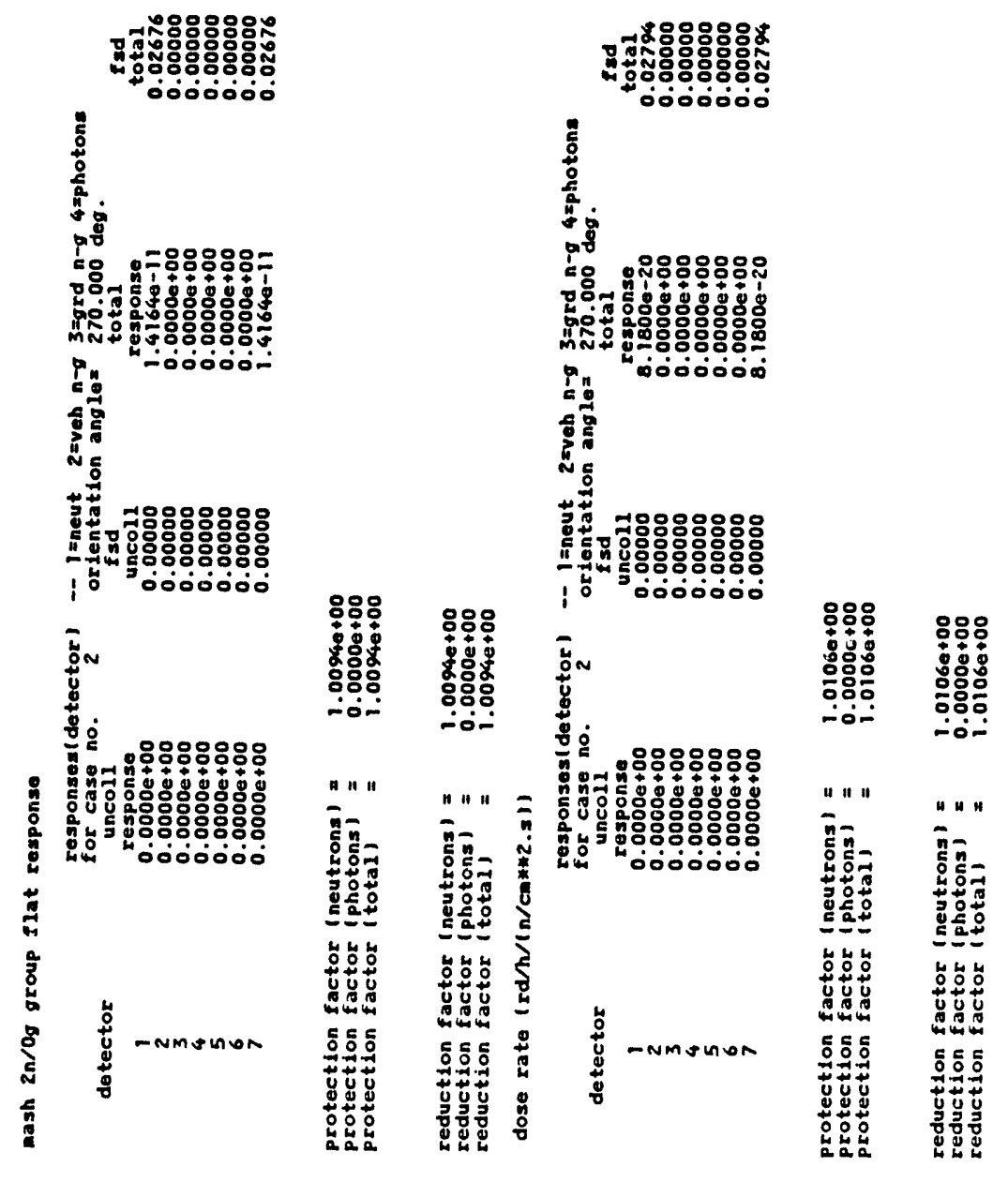




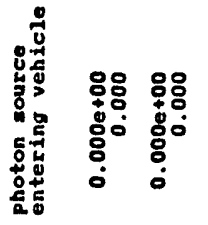

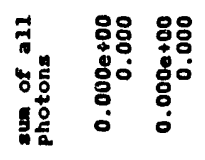
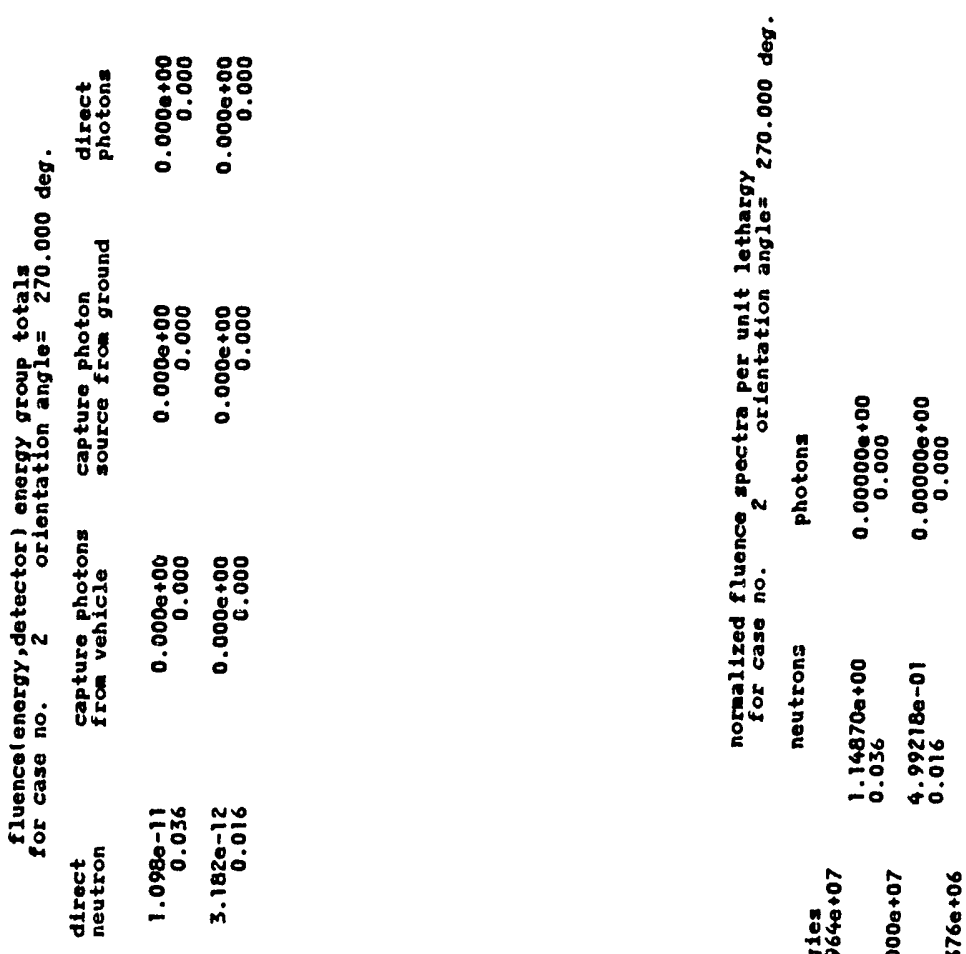

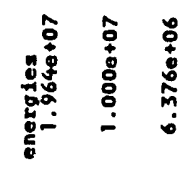

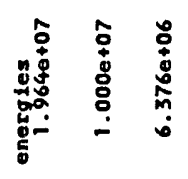




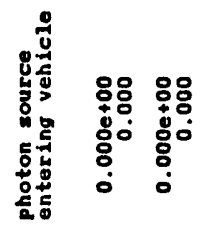

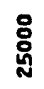

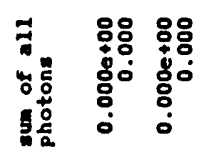
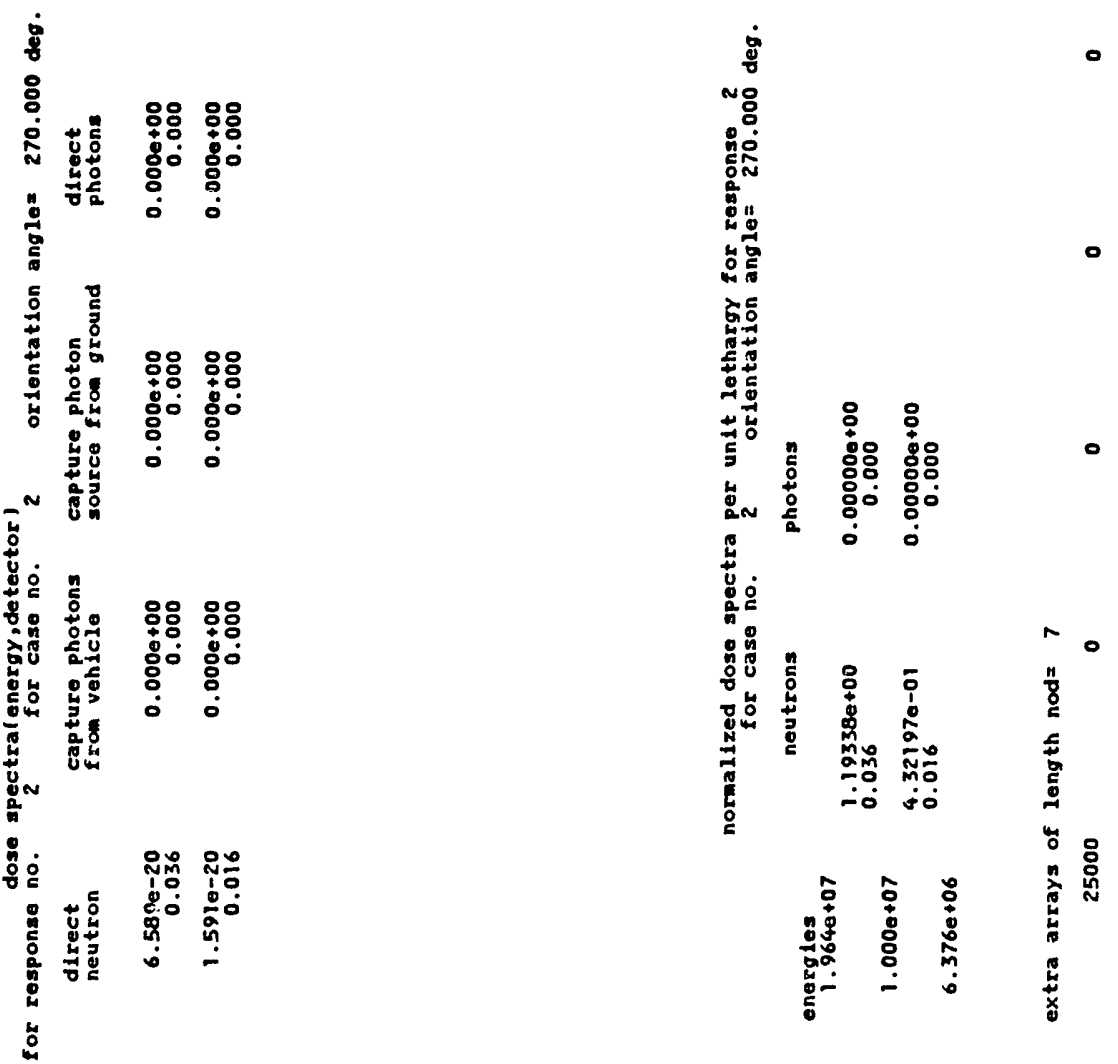

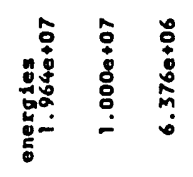



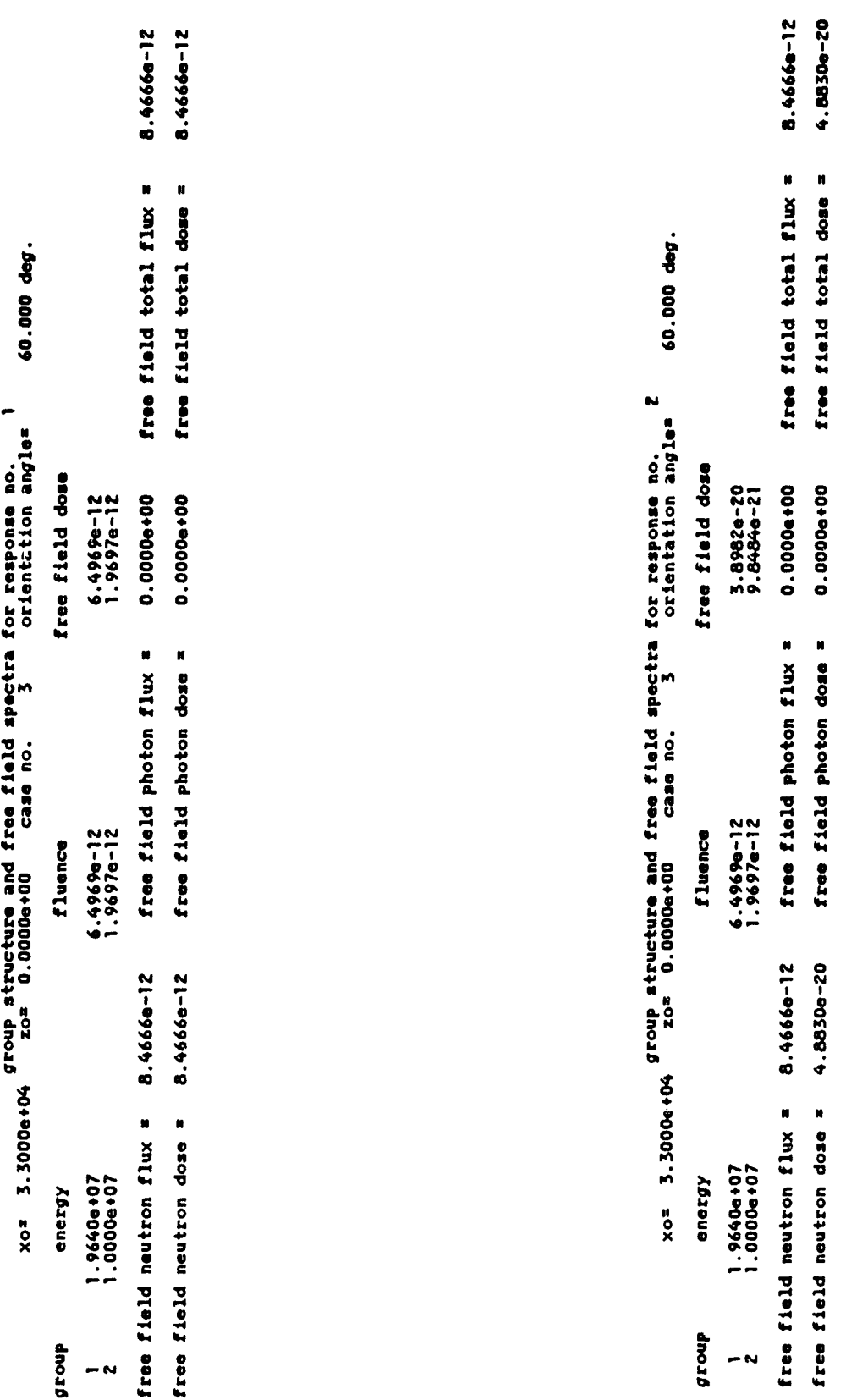

一

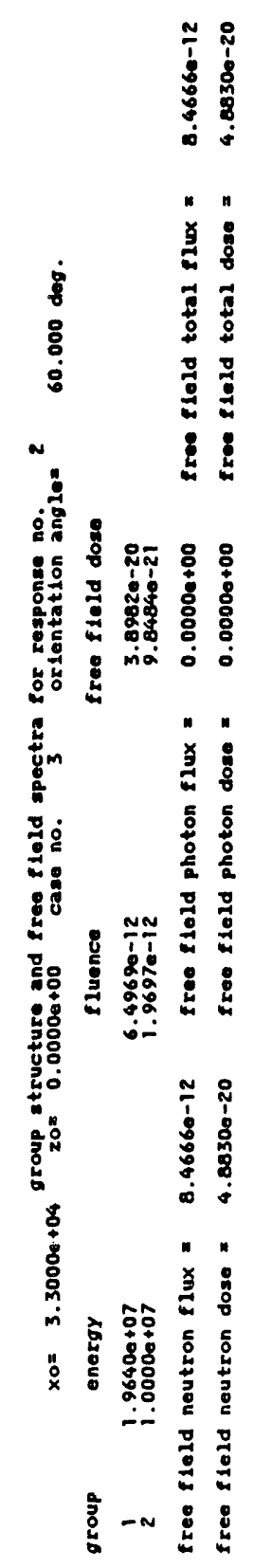

:

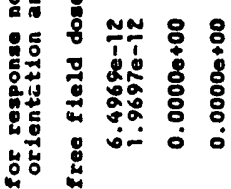

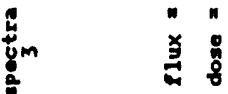

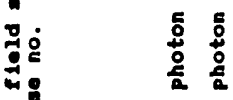

\&

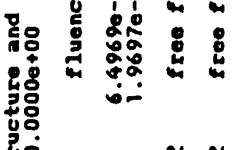

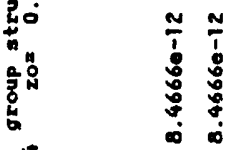

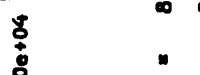

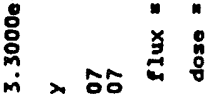

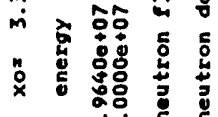

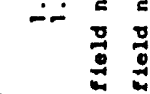

总 $-\mathrm{Q}$ 


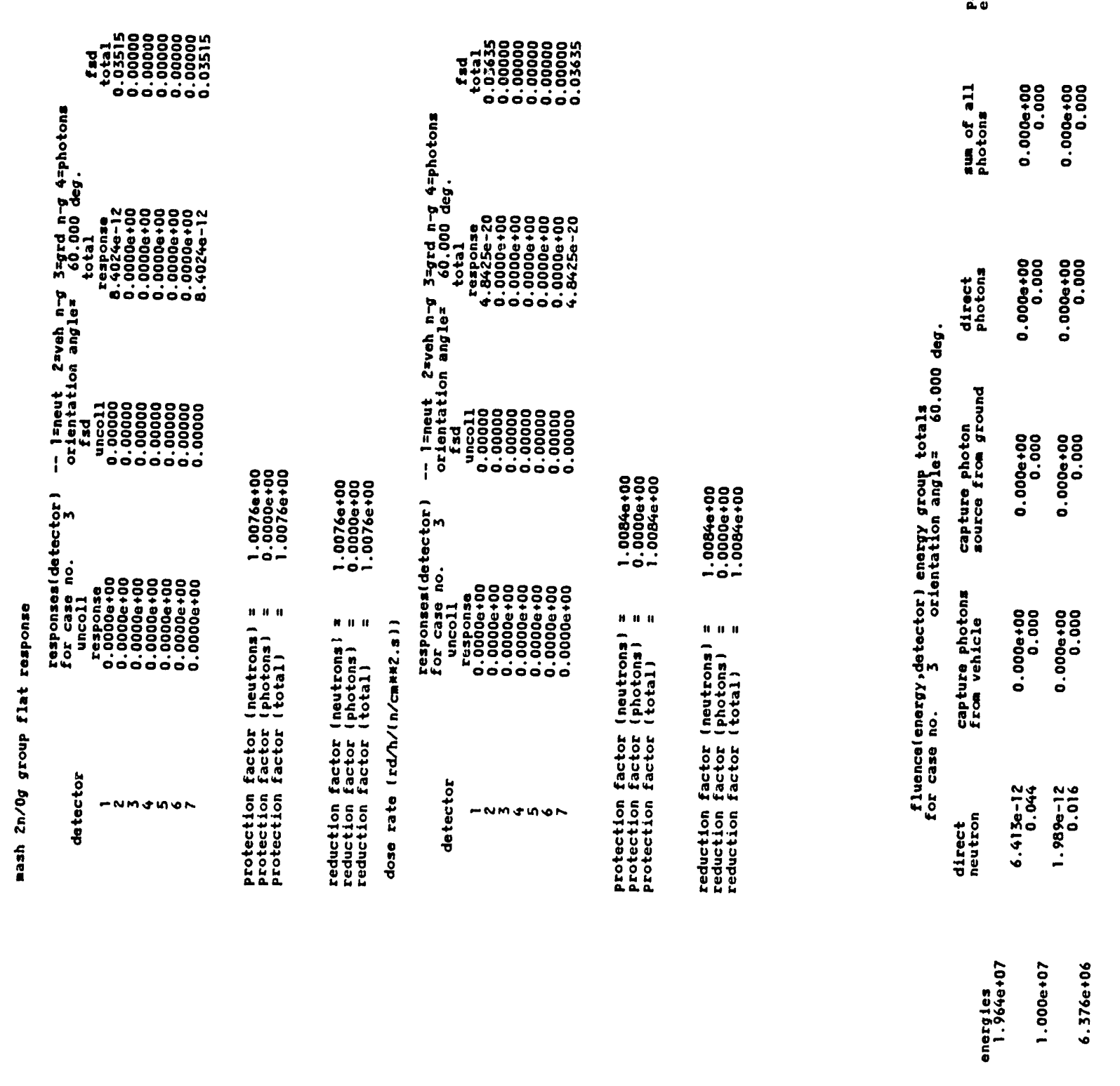



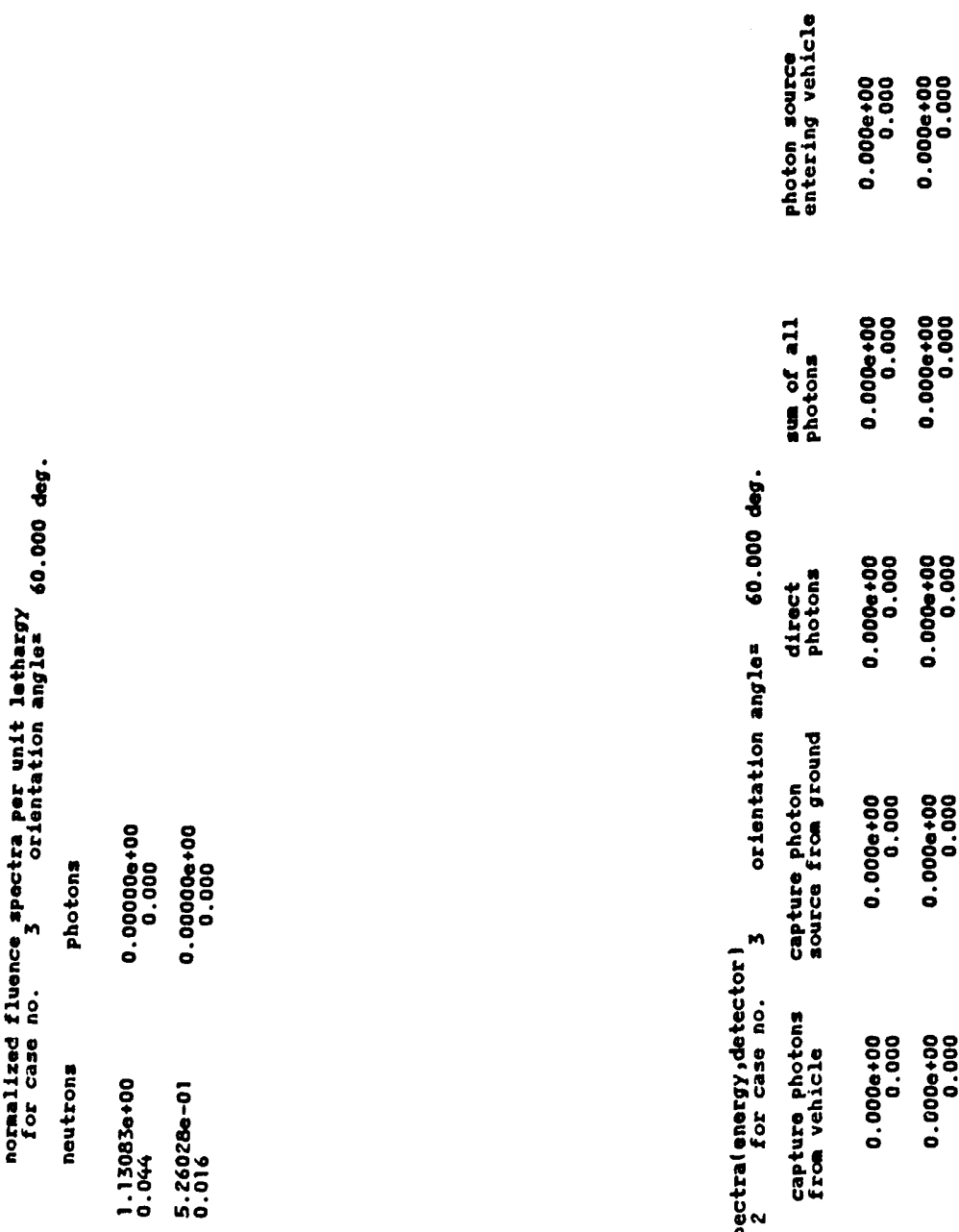

8

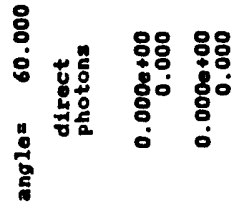

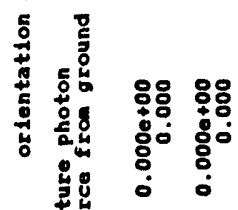

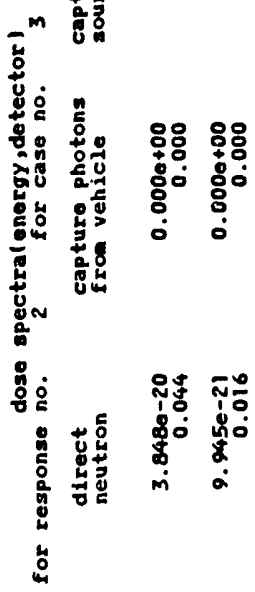

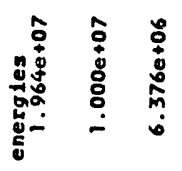

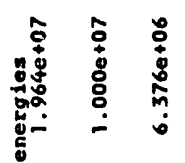



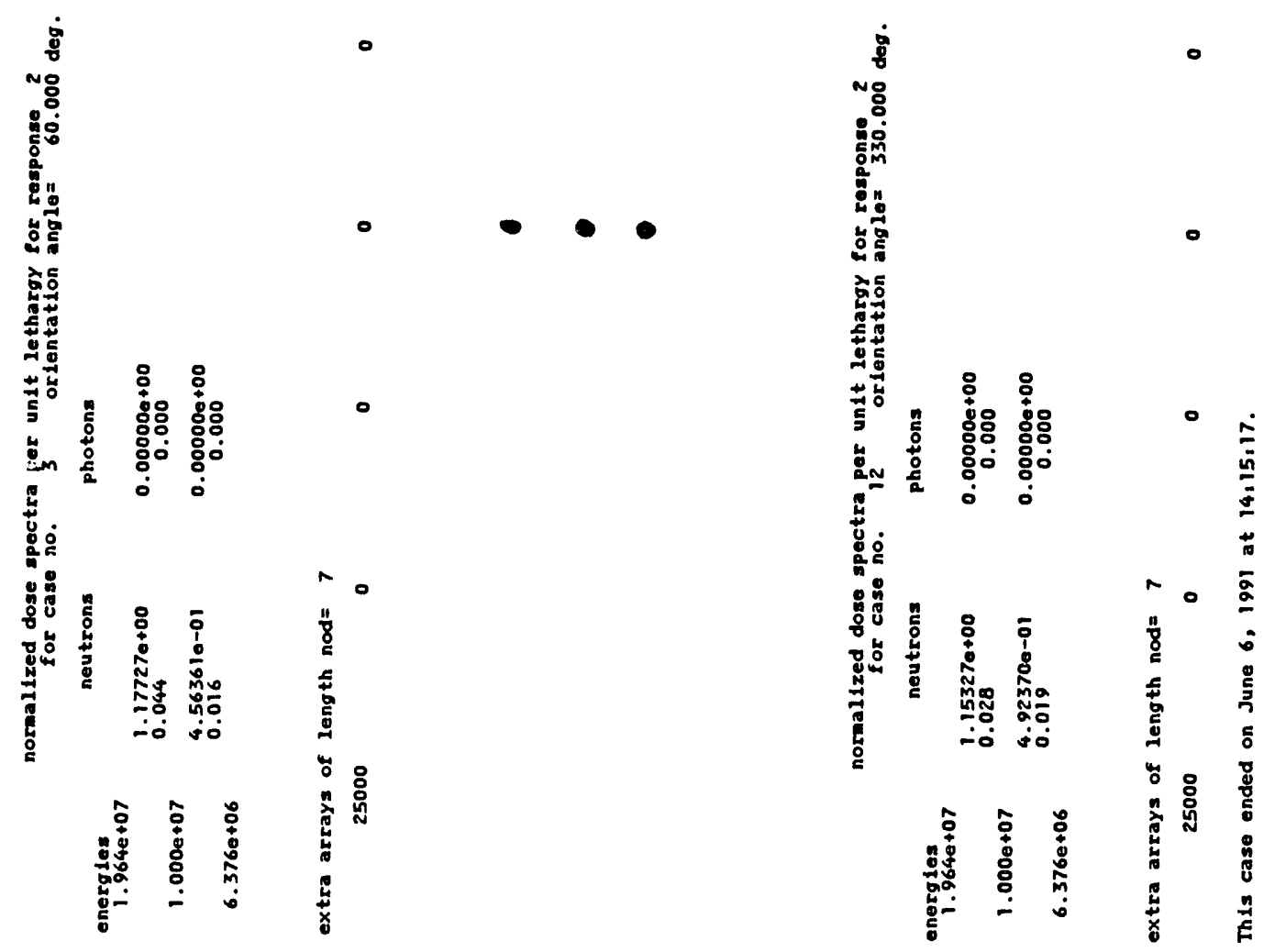
ORNL/TM-11873

\section{INTERNAL DISTRIBUTION}

1. F. S. Alsmiller

2. R. G. Alsmiller, Jr.

3. B. R. Appleton

4. J. M. Barnes

5. B. L. Bishop

6. T. J. Burns

7. R. L. Childs

8. S. N. Cramer

9. J. D. Drischler

10. M. B. Emmett

11. W. W. Engle, Jr.

12. T. A. Gabriel

13. D. T. Ingersoll

14. J. O. Johnson

15. R. A. Lillie

16. J. V. Pace III

17. L. M. Petrie
18. S. A. Raby

19. W. A. Rhoades

20. R. W. Roussin

21. R. T. Santoro

22-26. C. O. Slater

27. M. S. Smith

28. R. C. Ward

29. A. Zucker

30-31. Laboratory Records Department

32. Laboratory Records, ORNL-RC

33. Document Reference Section

34. Central Research Library

35. ORNL Patent Section

\section{EXTERNAL DISTRIBUTION}

36. Office of Assistant Manager for Energy Research and Development, DOE-OR, Oak Ridge TN 37830

37. Professor Roger W. Brockett, Harvard University, Pierce Hall, 29 Oxford Street, Cambridge MA 02138

38. John J. Dorning, Department of Nuclear Engineering and Physics, Thornton Hall, McCormick Road, University of Virginia, Charlottesville VA 22901

39. James E. Leiss, Rt. 2 Box 142C, Broadway VA 22815

40. Neville Moray, University of Illinois, Dept. of Mechanical and Industrial Engineering, 1206 West Green Street, Urbana IL 61801

41. Robert Young, Director, Defense Nuclear Agency, ATTN: RARP, 6801 Telegraph Road, Alexandria VA 22310

42. Mary F. Wheeler, Department of Mathematical Sciences, Rice University, P. O. Box 1892, Houston TX 77251

43-276. Defense Nuclear Agency Transport Distribution (AU)

277-288. Office of Scientific and Technical Information 
